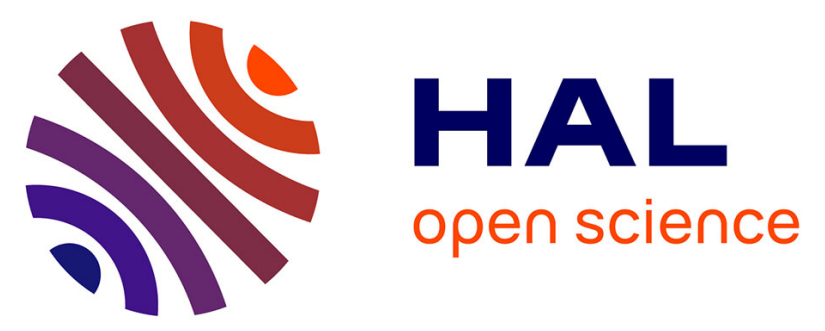

\title{
Sulfonic-functionalized algal/PEI beads for scandium, cerium and holmium sorption from aqueous solutions (synthetic and industrial samples)
}

Mohammed Hamza, Khalid A.M. Salih, Adel A.-H. Abdel-Rahman, Yasser Zayed, Yuezhou Wei, Jie Liang, Eric Guibal

\section{To cite this version:}

Mohammed Hamza, Khalid A.M. Salih, Adel A.-H. Abdel-Rahman, Yasser Zayed, Yuezhou Wei, et al.. Sulfonic-functionalized algal/PEI beads for scandium, cerium and holmium sorption from aqueous solutions (synthetic and industrial samples). Chemical Engineering Journal, 2021, 403, pp.126399. 10.1016/j.cej.2020.126399 . hal-02913590

\section{HAL Id: hal-02913590 https://hal.mines-ales.fr/hal-02913590}

Submitted on 6 Sep 2021

HAL is a multi-disciplinary open access archive for the deposit and dissemination of scientific research documents, whether they are published or not. The documents may come from teaching and research institutions in France or abroad, or from public or private research centers.
L'archive ouverte pluridisciplinaire HAL, est destinée au dépôt et à la diffusion de documents scientifiques de niveau recherche, publiés ou non, émanant des établissements d'enseignement et de recherche français ou étrangers, des laboratoires publics ou privés. 


\title{
Sulfonic-functionalized algal/PEI beads for scandium, cerium and holmium sorption from aqueous solutions (synthetic and industrial samples)
}

\author{
Mohammed F. Hamza ${ }^{\mathrm{a}, \mathrm{b}, 1}$, Khalid A.M. Salih ${ }^{\mathrm{a}, 2}$, Adel A.-H. Abdel-Rahman ${ }^{\mathrm{c}, 3}$, Yasser E. Zayed ${ }^{\mathrm{c}, 4}$, \\ Yuezhou Wei $^{\mathrm{a}, \mathrm{d}, 5}$, Jie Liang ${ }^{\mathrm{a}, *, 6}$, Eric Guibal ${ }^{\mathrm{e}, *, 7}$ \\ ${ }^{a}$ Guangxi Key Laboratory of Processing for Non-ferrous Metals and Featured Materials, School of Resources, Environment and Materials, Guangxi University, Nanning \\ 530004, PR China \\ ${ }^{\mathrm{b}}$ Nuclear Materials Authority, POB 530, El-Maadi, Cairo, Egypt \\ ${ }^{\mathrm{c}}$ Faculty of Science, Menoufia University, Shebine El-Koam, Egypt \\ d Shanghai Jiao Tong University, Shanghai, China \\ ${ }^{\mathrm{e}}$ IMT - Mines Ales, Polymers Composites \& Hybrids (PCH), F-30319 Alès Cedex, France
}

- The sulfonation of algal/PEI composite beads produce very efficient sorbent for Sc.

- The sorption process is fast (30-40 min equilibrium time).

- At $\mathrm{pH}_{\mathrm{eq}} \sim 4$, the maximum sorption

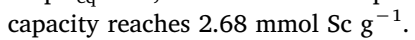

- Rare earth elements totally desorbed using $\mathrm{HCl} / \mathrm{CaCl}_{2}$, with good sorbent recycling.

- REEs strongly enriched onto S-A $\mathrm{A}_{\mathrm{L}} \mathrm{PEI}$ after the treatment of a red mud solution.
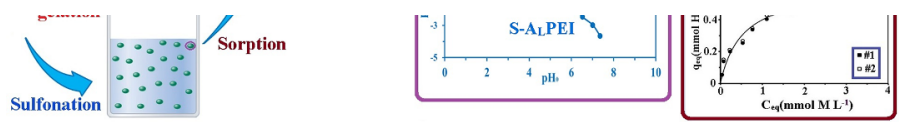

Keywords:

Polyethyleneimine biocomposite

Sulfonation

Rare earth

Sorption isotherms

Uptake kinetics

Metal desorption and sorbent recycling

\begin{abstract}
A B S T R A C T
The one-pot synthesis of algal biomass/polyethyleneimine beads, $\mathrm{A}_{\mathrm{L}} \mathrm{PEI}$ (electrostatic interaction followed by calcium ionotropic gelation), produces a stable sorbent whose sorption properties for rare earth elements (REEs) are significantly improved by functionalization. The grafting of sulfonic groups (S-A $\left.A_{L} P E I\right)$, which have high affinity for REEs, increases sorption capacities as high as $2.68 \mathrm{mmol} \mathrm{sc} \mathrm{g}^{-1}, 0.61 \mathrm{mmol} \mathrm{Ce} \mathrm{g}^{-1}$ and $0.53 \mathrm{mmol}$ $\mathrm{Ho}^{-1}$, at $\mathrm{pH}$ close to 4 (equilibrium $\mathrm{pH}$ ). Sorption isotherms are fitted by the Langmuir equation for scandium and cerium; for holmium, the Freundlich and the Sips equations show better fits. Sorption occurs within 30-40 min; kinetic profiles are fitted by the pseudo-first order rate equation and the Crank equation (resistance to intraparticle diffusion). The sorbent has a marked preference for Sc(III) against Ce(III) and Ho(III) (confirmed by selectivity tests). The sorbent is also selective for REEs against alkali-earth elements. The three metals are readily desorbed (within 20-30 $\mathrm{min}$ ) using $\mathrm{HCl} / \mathrm{CaCl}_{2}$ solution. Desorption remains higher than $99 \%$ for 5 cycles while sorption performance is decreased by less than $6 \%$ at the fifth cycle. The sorbent is tested for the recovery of valuable metals from red mud solution at different $\mathrm{pH}$ values. Despite the large excess of heavy metals in the industrial solution, $\mathrm{S}-\mathrm{A}_{\mathrm{L}} \mathrm{PEI}$ shows a good affinity for REEs at $\mathrm{pH}$ close to 3.46 with important enrichment factors (in the range 19-118 depending on the metal). The material is fully characterized by BET, TGA, FTIR, XPS, elemental analysis, titration and SEM-EDX analysis. The sorption involves different mechanisms (on amine and sulfonic groups) including electrostatic attraction and chelation depending on $\mathrm{pH}$ and metal speciation.
\end{abstract}

\footnotetext{
* Corresponding authors at: Guangxi Key Laboratory of Processing for Non-ferrous Metals and Featured Materials, School of Resources, Environment and Materials, Guangxi University, Nanning 530004, PR China (J. Liang), IMT - Mines Ales, Polymers Composites \& Hybrids (PCH), F-30319 Alès Cedex, France (E. Guibal).

E-mail addresses: m_fouda21@hotmail.com (M.F. Hamza), Immortaltiger7@gmail.com (K.A.M. Salih), adelnassar63@yahoo.com (A.A.-H. Abdel-Rahman),

Zayed_yasser@yahoo.com (Y.E. Zayed),yzwei@gxu.edu.cn (Y. Wei), liangj@gxu.edu.cn (J. Liang), eric.guibal@mines-ales.fr (E. Guibal).
}

${ }^{1}$ 0000-0002-8935-6884

${ }^{2} 0000-0001-6117-6753$

${ }^{3}$ 0000-0003-3319-8191

${ }^{4} 0000-0002-1364-1312$

${ }^{5}$ 0000-0003-3821-9078

${ }^{6}$ 0000-0002-0904-614X

${ }^{7}$ 0000-0002-2767-6305 


\section{Introduction}

The amazing development of High-tech industry sectors (electronic devices, special magnets, screens, etc.) induces a growing demand for precious and strategic metals like rare earth elements (REEs). More specifically, the rarefaction and the geopolitical pressure of the resource for REEs have driven many governmental and intergovernmental agencies to publish recommendations or incentive politics [1] for promoting the recycling of these metals from wastes (DEEs) [2-7] and their recovery from secondary sources (sub-products) [2,8-12].

The recovery of REEs from secondary sources may involve pyrometallurgical steps (oxidation/roasting) [13-15]; however, acidic leaching remains the technique the most frequently used for processing wastes and secondary resources [14,16-19]. This first step in the process transfers target metals (and other base metals) from solid to leachates that require complementary steps for enriching, separating and recovering the metals. Different techniques may be used depending on the relative concentrations of the metals, and the composition of the solutions. Solvent extraction is frequently used for the treatment of relatively concentrated solutions (higher than a few hundred $\mathrm{mg} \mathrm{L}^{-1}$ ) $[6,20-24]$. Precipitation processes are rarely applied because of poor selectivity that makes the separation of REEs from heavy metals relatively difficult. For low concentrations, sorption processes are preferred for separating and enriching target metals on the sorbent (and further in the eluates of saturated sorbents).

Extractant-impregnated resins have been used for REEs recovery from acidic solutions, making profit of the high affinity and fast transfer properties of extractants immobilized in the porosity of the supports (which prevents dissolution and dispersion of toxic and expensive compounds) [25-28]. More frequently, ion exchange and chelating resins (which may bear similar reactive groups than those identified on extractants) are used for the removal of REEs from acidic leachates $[29,30]$. Nanomaterials have been used in order to minimize mass transfer limitations [31], at the expense of difficulties in solid/liquid separation. Magnetic-based microparticles obtained by incorporation of magnetite into a functionalized polymer may represent an improvement in separation while maintaining good sorption performance [32-34]. More conventional sorbents may include ion-exchange resins [35-39] and chelating resins [25,40-42].

Resins bearing sulfonic-based groups have demonstrated a good affinity for REEs, being mono-functional resins such as Dowex $50 \mathrm{~W}$ X8 [36], Purolite C-100 [39] or multi-functional resins such as Diphonix resins (bearing sulfonic, diphosphonic and carboxylic groups) [43] or Purolite family [41].

Recently, a new generation of bio-based (spherical) resins has been developed using the interactions of alginate and algal biomass (including a partial in situ extraction of alginate contained in cell wall) with branched polyethyleneimine (bPEI). By itself, PEI is highly efficient for metal complexation and sorption (when conditioned as solid particles or cryogels) [44]. In combination with algal biomass, these supports bearing both amine (primary, secondary and tertiary amine groups) for PEI and carboxylic groups for alginate/algal fraction have a broad intrinsic affinity for metal ions depending on the charge (and speciation) of metal ions, the $\mathrm{pH}$ (and the charge hold by the sorbent). However, these reactive groups (especially the amine groups) also offer high reactivity for the functionalization of the support. A portfolio of derivatives of these algal/PEI beads (APEI and APEI*) is currently in development. Amidoximated [45] and quaternized [46,47] functionalized beads were successively developed for Sr(II) and for both Sc(III) and $\mathrm{U}(\mathrm{VI})$, respectively. The current work focuses on the development of a new member of this family of bio-based resins. Another (more environmentally-friendly) process was used for manufacturing algal/ PEI beads $\left(\mathrm{A}_{\mathrm{L}} \mathrm{PEI}\right)$ without addition of alginate. The alginate used for the structuration of the material is only produced by the extraction of the biopolymer from algal cell wall (Laminaria digitata). In addition, a sulfonate process is used for preparing sulfonic-bearing $\mathrm{A}_{\mathrm{L}} \mathrm{PEI}$ beads (i.e., $\left.S-A_{L} P E I\right)$. The reported affinity of strong acid ion-exchange resins for REEs justifies the application of the sulfonated bio-based sorbent for their recovery from aqueous solutions. This new sorbent is tested here for the sorption of Sc(III), Ce(III) and Ho(III). These metal ions have been selected for illustrating different families within REEs. Though Sc (III) is not formally a REE, it is frequently associated with REE family due to similar physicochemical properties but with much lighter atomic weight (i.e., $44.956 \mathrm{~g} \mathrm{~mol}^{-1}$ ); Ce(III) is representative of light REEs (LREEs, $140.1165 \mathrm{~g} \mathrm{~mol}^{-1}$ ), while Ho(III) is a member of heavy REEs (HREEs, $164.930 \mathrm{~g} \mathrm{~mol}^{-1}$ ). Checking these three metals will help in evaluating the eventual selectivity of the sorbent within REE family.

In the first part, the sorbent is characterized by SEM and SEM-EDX analysis, FTIR and XPS spectroscopies, BET surface analysis, thermogravimetric analysis, $\mathrm{pH}_{\mathrm{PZC}}$ and elemental analysis for the interpretation of chemical functionalization and the approach of sorption mechanisms. In a second step, the sorption properties are studied with attention to the effect of the $\mathrm{pH}$, the comparison of uptake kinetics (at different levels of saturation of the sorbent), and the evaluation of sorption isotherms. This is completed by a study of metal desorption and the recycling of the sorbent. The selectivity of the sorbent for target metal ions in the presence of alkali-earth metals is investigated prior to testing the efficiency of the sorbent for metal recovery from complex solutions (pre-treated red mud effluent).

\section{Materials and methods}

\subsection{Materials}

Algal biomass (Laminaria digitata) was kindly supplied by Setalg (Pleubian, France). After grinding, algal biomass was sieved and particles below $250 \mu \mathrm{m}$ were used for preparing the raw beads. Branched polyethylenemine (PEI, 50\%, w/w in water), glutaraldehyde (GA, 50\%, $\mathrm{w} / \mathrm{w}$ in water) and sulfosuccinic acid were supplied by Sigma-Aldrich (Taufkirchen, Germany). Methanol and poly(ethyleneglycol) diglycidyl ether (crosslinking agent) were purchased from Shanghai Macklin Biochemical Co., Ltd. (Shanghai, China). $\mathrm{Na}_{2} \mathrm{CO}_{3}$ and $\mathrm{CaCl}_{2}$ were provided by Chem-Lab NV (Zedelgem, Belgium).

\subsection{Sorbent synthesis}

\subsubsection{Production of Algal/PEI beads ( $A_{L}$ PEI) (Scheme 1)}

Composite homogeneous algal/PEI beads were prepared by a threestep procedure: (a) partial alginate extraction from algal biomass, (b) mixing with PEI solution, and (c) ionotropic gelation. Finally, the beads were freeze-dried $\left(-52{ }^{\circ} \mathrm{C}, 0.1 \mathrm{mbar}\right)$ for two days. 
Algal biomass ( $L$. digitata) was grinded and sieved; the fraction below $250 \mu \mathrm{m}$ was collected and dispersed (30 g) into $800 \mathrm{~mL}$ of $\mathrm{Na}_{2} \mathrm{CO}_{3}$ solution $(1 \% \mathrm{w} / \mathrm{w})$. The suspension was maintained under agitation at $50{ }^{\circ} \mathrm{C}$ for $24 \mathrm{~h}$. This step allows the partial extraction of alginate contained into the algae. The suspension was then mixed with $5 \mathrm{~mL}$ of PEI $(50 \%, \mathrm{w} / \mathrm{w})$; the homogeneous suspension was dropped into $2 \mathrm{~L}$ of $\mathrm{CaCl}_{2}$ solution $(1 \%, \mathrm{w} / \mathrm{w})$. This step consists of the ionotropic gelation of alginate extracted from algal biomass: carboxylate groups interact with calcium ions for the jellification of the mixture. The interaction of protonated amine groups of PEI with carboxylate groups also contributes to stabilize the beads (double interpenetrating network: alginate/PEI and alginate/Ca(II).

\subsubsection{Functionalization of $A_{L} P E I$ beads - Sulfonation ( $\left.S-A_{L} P E I\right)$}

Five grams of $A_{L}$ PEI beads were immersed in $90 \mathrm{~mL}$ of methanol containing $25 \mathrm{~g}$ of sulfosuccinic acid. The mixture was gently stirred (at $105( \pm 5) \mathrm{rpm}$ ), at room temperature (i.e., $22 \pm 2{ }^{\circ} \mathrm{C}$ ) for $24 \mathrm{~h}$. In a second step, $3 \mathrm{~mL}$ of poly(ethyleneglycol) diglycidyl ether was added to the mixture for improving the stability of the sorbent. The reagent was added drop by drop for $10 \mathrm{~min}$, and the temperature was raised to $70{ }^{\circ} \mathrm{C}$ for $5 \mathrm{~h}$. The sulfonated beads (S-A $\mathrm{A}_{\mathrm{L}} \mathrm{PEI}$ ) were filtered off, successively washed with water and methanol, before being freeze dried for $24 \mathrm{~h}$. The Scheme 1 shows the expected structure of the functionalized material. This is inspired by the mechanism of sulfonation described by Rhim et al. [48] for the sulfonation of poly(vinyl alcohol).

\subsection{Sorbent characterization}

A Phenom ProX scanning electron microscope (SEM, Thermo Fisher Scientific, Netherlands) was used for the characterization of the morphology of sorbent beads. The integrated EDX tool of the SEM was used for the semiquantitative analysis of sorbent surfaces. A Micromeritics TriStar II (Norcross, GA, USA) was operated for the textural analysis of the samples (which were degassed at $100{ }^{\circ} \mathrm{C}$, for $12 \mathrm{~h}$ before analysis). More specifically, the $\mathrm{BJH}$ method was used for the quantification of specific surface area and the determination of the pore size distribution. Elemental analysis was performed with a Vario EL cube element analyzer (Elementar Analysensysteme $\mathrm{GmbH}$, Langenselbold, Germany). Thermal analysis of the sorbents was carried out operating a Netzsch STA 449 F3 Jupiter (NETZSCH-Gerätebau GmbH, Selb, Germany) (temperature ramp: $10{ }^{\circ} \mathrm{C}$ / min) under nitrogen atmosphere. FTIR spectra were acquired on dried samples (dispersed into KBr discs) using an IRTracer-100 (Shimadzu, Tokyo, Japan). An ESCALAB 250XI + instrument (Thermo Fischer Scientific, Inc., Waltham, MA, USA) was operated for collecting XPS spectra of the materials (before and after metal sorption). The $\mathrm{pH}$-drift method was carried out for determining the $\mathrm{pH}_{\mathrm{PZC}}$ of the sorbent. The sorbent $(100 \mathrm{mg})$ was mixed for $48 \mathrm{~h}$ with $50 \mathrm{~mL}$ of a series of $0.1 \mathrm{M} \mathrm{NaCl}$ whose initial $\mathrm{pH}\left(\mathrm{pH}_{0}\right)$ was controlled between 1 and 11 . The final $\mathrm{pH}\left(\mathrm{pH}_{\mathrm{eq}}\right)$ was monitored using a Mettler Toledo $\mathrm{pH}$-meter (Mettler, Colombus, $\mathrm{OH}, \mathrm{USA}$ ). The $\mathrm{pH}_{\mathrm{PZC}}$ is obtained for unchanged $\mathrm{pH}\left(\mathrm{pH}_{0}=\mathrm{pH}_{\mathrm{eq}}\right)$.

\subsection{Sorption studies}

The study of sorption properties was carried out in batch. The sorbent $(\mathrm{m}, \mathrm{g})$ was mixed with a volume of solution $(\mathrm{V}, \mathrm{L})$ containing target metal ions $\left(\mathrm{C}_{0}, \mathrm{mg} \mathrm{L}^{-1}\right.$ or $\left.\mathrm{mmol} \mathrm{L}^{-1}\right)$ at fixed initial $\mathrm{pH}$. The sorbent dosage is defined by $\mathrm{SD}\left(\mathrm{g} \mathrm{L}^{-1}\right)=\mathrm{m} / \mathrm{V}$. The agitation speed was set at $170 \mathrm{rpm}$. Standard temperature was $22 \pm 2{ }^{\circ} \mathrm{C}$. At equilibrium (or a fixed contact times for the study of uptake kinetics), samples were collected, filtrated on filter membrane (pore size: $1.2 \mu \mathrm{m}$ ). The residual concentration $\left(\mathrm{C}_{\mathrm{eq}}, \mathrm{mg} \mathrm{L}^{-1}\right.$ or $\left.\mathrm{mmol} \mathrm{L}^{-1}\right)$ was measured using an inductively-coupled plasma atomic emission spectrometer (ICP-AES, ICPS-7510 Shimadzu, Tokyo, Japan). The sorption capacity ( $\mathrm{q}_{\mathrm{eq}}, \mathrm{mmol}$ $\left.\mathrm{g}^{-1}\right)$ was deduced from mass balance equation: $\mathrm{q}_{\mathrm{eq}}=\left(\mathrm{C}_{0}-\mathrm{C}_{\mathrm{eq}}\right) \times \mathrm{V} / \mathrm{m}$. For the study of desorption kinetics, the samples were collected at the end of uptake kinetics and submitted to desorption test. The desorption was carried out using a $0.2 \mathrm{M} \mathrm{HCl} / 0.5 \mathrm{M} \mathrm{CaCl}_{2}$ solution; the sorbent dosage was set at $1 \mathrm{~g} \mathrm{~L}^{-1}$. Samples collected at fixed contact times, were filtrated and the concentration of target metals was analyzed by ICPAES for evaluating desorption yield. The recycling of the sorbent (for five successive cycles) was tested using the same batch procedures; a rinsing step was systematically intercalated between each sorption and desorption step. Full experimental conditions are systematically reported in the caption of the Figures.

Conventional models were used for modeling kinetic profiles (i.e., pseudo-first and pseudo second-order rate equations [49], Crank equation for fitting the resistance to intraparticle diffusion [50]) and sorption isotherms (i.e., Langmuir, Freundlich and Sips equations, [51]). The parameters were determined by non-linear regression analysis using Mathematica ${ }^{\circledR}$ facilities. The fitting of experimental profiles were compared by the comparison of determination coefficients (which were calculated through the linear regression analysis of fitted data against experimental values) and AIC (Akaike information criterion [52]). The relevant equations are reported in Tables AM 1-2 (see Additional Material Section).

\subsection{Application to ore leachate}

The industrial sample, bearing Sc and REE, was collected form Jinnao-Ti company in Tengixan, Guangxi (China). This effluent, generated in the production of red mud, is highly acid ("negative" value); the $\mathrm{pH}$ of the leaching solution was controlled using $0.1 / 1 \mathrm{M} \mathrm{H}_{2} \mathrm{SO}_{4}$ or $\mathrm{NaOH}$ solutions. This complex solution contains several heavy metal and REEs (i.e., Fe, Al, Zr, Mo, Ti, $\mathrm{Zn}$ and REEs) and Si. Their recovery was investigated using $\mathrm{S}-\mathrm{A}_{\mathrm{L}} \mathrm{PEI}$ on a wide $\mathrm{pH}_{0}$ range (i.e., $\mathrm{pH} 1-5$ ). The suspension was maintained under agitation for $24 \mathrm{~h}$ and $48 \mathrm{~h}$ at room temperature. After filtration (on filter membrane), the residual concentration of the metal ions in the solution was analyzed by ICP-AES for determining sorption capacities, distribution ratios, and selectivity coefficients. In addition, for sorbents collected at $\mathrm{pH}_{0} 3,4$ and 5 , the content in the different metals was determined at the surface and in the core of the beads using semi-quantitative EDX analysis.

\section{Results and discussion}

\subsection{Sorbent characterization}

\subsubsection{Textural properties}

The functionalization of $A_{L}$ PEI involves a little increase in the specific surface area of the sorbent (from 6 to almost $15 \mathrm{~m}^{2} \mathrm{~g}^{-1}$, Table AM3). The porous volume is also increased from $0.0224 \mathrm{~cm}^{3} \mathrm{~g}^{-1}$ to $0.058 \mathrm{~cm}^{3} \mathrm{~g}^{-1}$. It is noteworthy that the textural characteristics of raw beads (i.e., $\mathrm{A}_{\mathrm{L}} \mathrm{PEI}$ ) are comparable for adsorption and desorption branches for nitrogen isotherms. This is not the case for functionalized material (i.e., S- $\mathrm{A}_{\mathrm{L}} \mathrm{PEI}$ ) the $\mathrm{BJH}$ desorption cumulative area is about twice the value found for adsorption compared with desorption branch (28.64 vs. $15.51 \mathrm{~m}^{2} \mathrm{~g}^{-1}$ ). Similar increases were observed for other criterion, such as BJH cumulative volume of pores (increased from 0.055 to $0.061 \mathrm{~cm}^{3} \mathrm{~g}^{-1}$ ). This is a direct consequence of the drastic change in BJH average pore width: $84.6 \AA$ for desorption branch $v s$. $143 \AA$ for adsorption branch. This difference between the two sorbents is clearly confirmed by the $\mathrm{N}_{2}$ isotherm curves (Figure AM1). For $\mathrm{A}_{\mathrm{L}} \mathrm{PEI}$, the adsorption isotherms can be considered a Type IIa isotherm according Rouquerol classification (with limited hysteresis loop, HL). On the opposite hand, the strong and typical hysteresis loop for adsorption/desorption branches mean that the material follows the Type IIb classification $[53,54]$. The hysteresis loop is associated with the socalled type $\mathrm{B}$, which is described by slit shaped pores, while the original material has a more regular hysteresis loop (qualified as Type A) where the pores are generally described as cylindrical pores. The grafting of sulfonic groups, through the reaction with sulfosuccinic acid, and/or the reaction with the crosslinking agent cause significant changes in the 


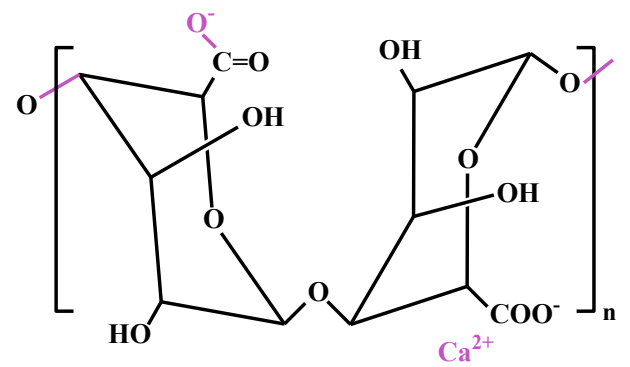

Algal biomass
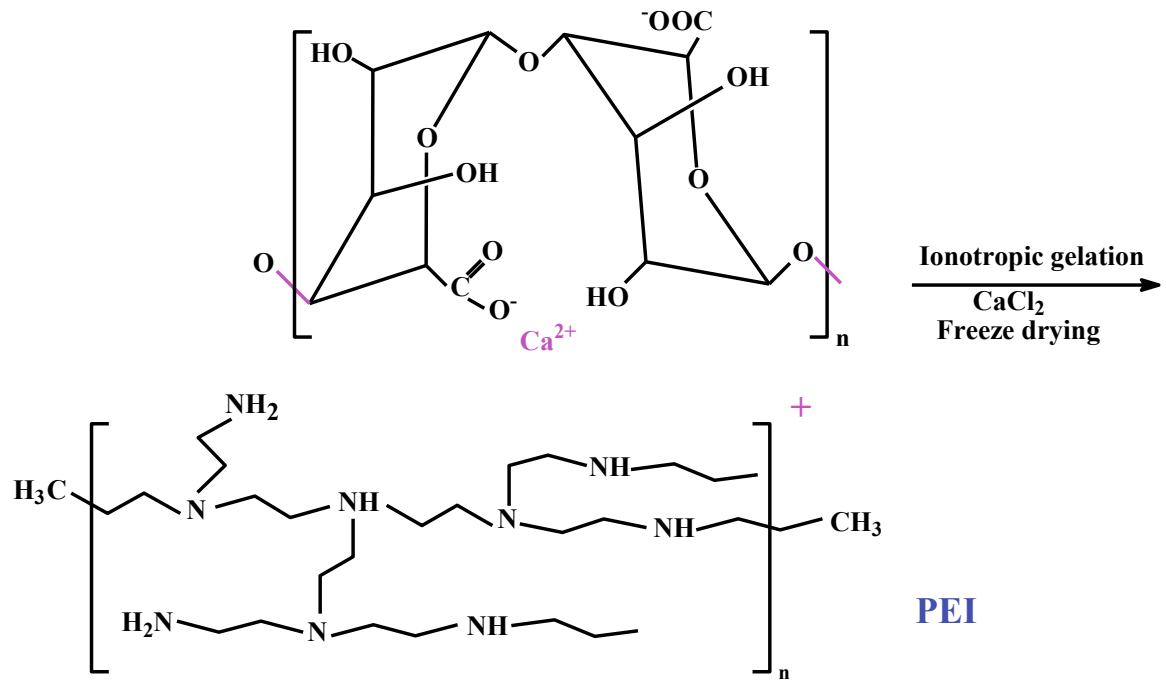

PEI

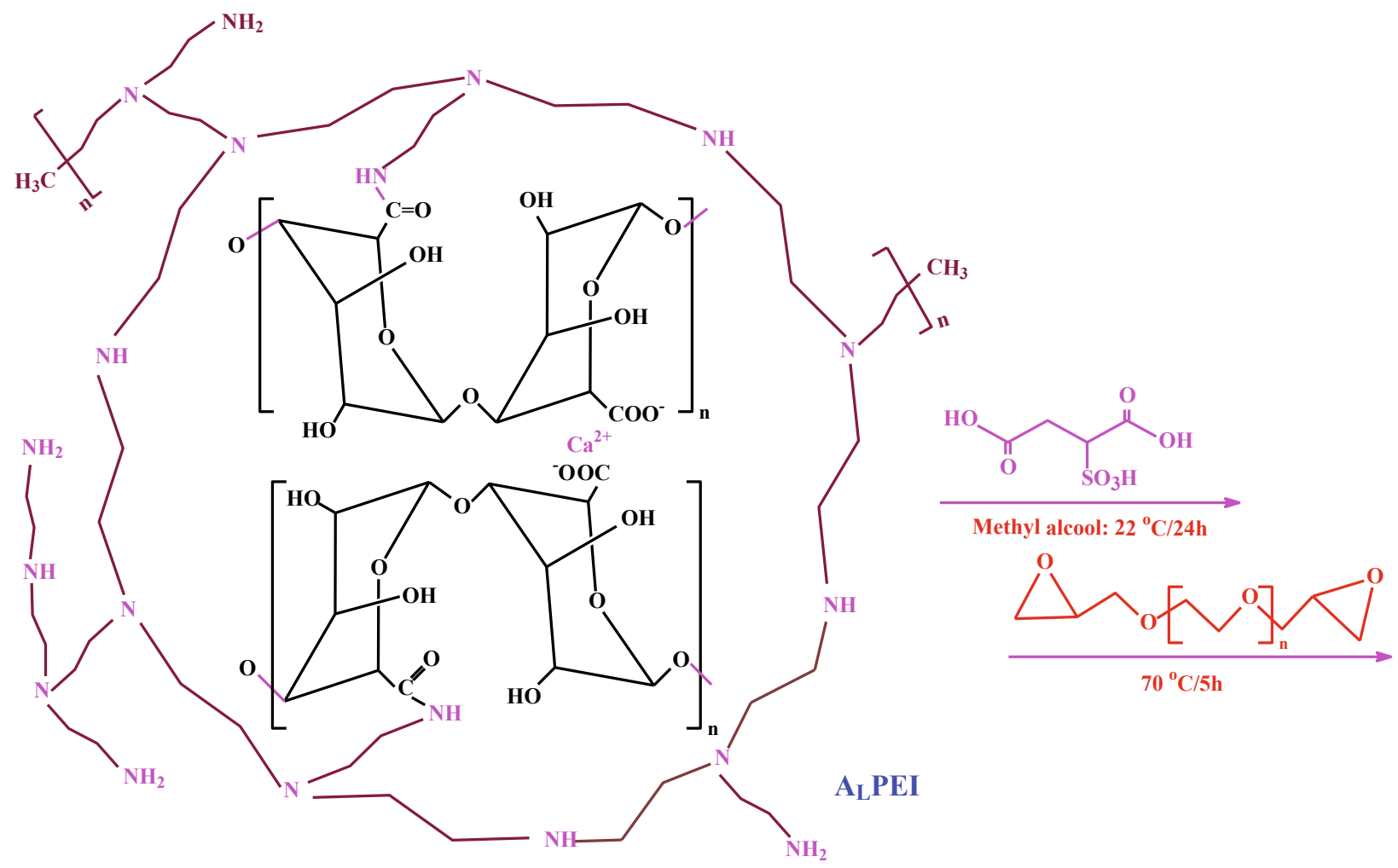

Scheme 1. Synthesis procedure - Expected (simplified) structure of the sorbent (algal biomass simplified to alginate active material). 


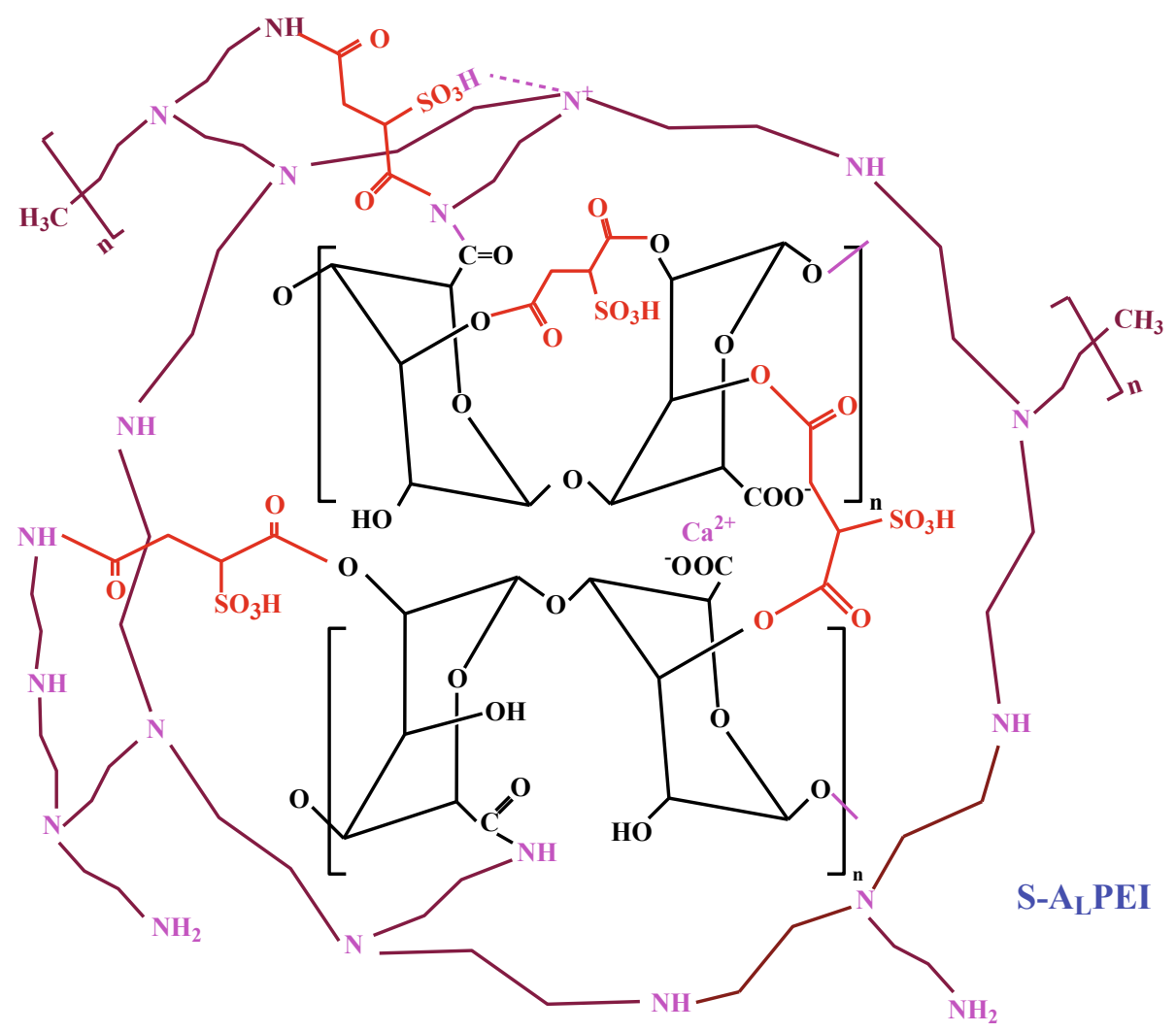

Scheme 1. (continued)

textural properties of the materials, which in turn, may influence the accessibility of reactive groups. According IUPAC classification, the sorbent can be considered macroporous; these macropores may also explain the weak porous volume (i.e., $0.024-0.058 \mathrm{~cm}^{3} \mathrm{~g}^{-1}$ ).

\subsubsection{Thermogravimetric analysis}

The thermogravimetric analysis (TGA) and the derivative thermogram (DTG) of both $A_{L}$ PEI and S- $A_{L}$ PEI are summarized in Figure AM2. The TGA curves for the two materials show a first step (below $192-194{ }^{\circ} \mathrm{C}$ ) that corresponds to the loss of physically adsorbed water (about $10-7.6 \%$ weight loss). In the case of $A_{L} P E I$, a series of wavelets is observed between 194 and $887{ }^{\circ} \mathrm{C}$; corresponding to valleys (or shoulders) on the DTG curve (at $243.14{ }^{\circ} \mathrm{C}, 320.71{ }^{\circ} \mathrm{C}$, and $427.59{ }^{\circ} \mathrm{C}$ ). The weight loss is associated with different modes of degradation corresponding to the decomposition of the amine groups PEI (below $250{ }^{\circ} \mathrm{C}$ ), followed by the decomposition of the double-network frame of alginate/PEI and alginate/Ca(II) [55], below $375{ }^{\circ} \mathrm{C}$. In the range $375-500{ }^{\circ} \mathrm{C}$, the depolymerization of alginate and PEI occurs, together with the char formation. New decomposition is observed above $690^{\circ} \mathrm{C}$; this is associated with the char decomposition (deep valley observed at $785.35{ }^{\circ} \mathrm{C}$ on DTG curve). The total weight loss is close to $68.5 \%$.

In the case of S- $\mathrm{A}_{\mathrm{L}} \mathrm{PEI}$, the degradation profile is much less marked: the wavelets are more difficult to detect. Similar observation was reported by Akköz et al. [56] in the case of sulfonated-agriculture waste. The DTG shows a shoulder at $152.84{ }^{\circ} \mathrm{C}$ (water release) and three valleys at $229.84,293.91$ and $370.89{ }^{\circ} \mathrm{C}$; the corresponding temperatures are lower than in the case of $\mathrm{A}_{\mathrm{L}} \mathrm{PEI}$. It is noteworthy that the deep valley observed during the decomposition of the char for $\mathrm{A}_{\mathrm{L}} \mathrm{PEI}$ almost disappears for $S-A_{L}$ PEI. The decomposition of the sulfonated sorbent is more progressive and the total weight loss increases to $73.81 \%$ (about $5 \%$ more than for raw beads). The functionalization of the sorbent slightly decreases the thermal stability of the material. In the case of Amberlyst 15 (strong cation exchanger), Fan et al. [57] reported the decomposition of sulfonic groups in the temperature range $200-400{ }^{\circ} \mathrm{C}$.

\subsubsection{FTIR spectroscopy}

Figure AM3 shows the comparison of FTIR spectra of $\mathrm{A}_{\mathrm{L}} \mathrm{PEI}$ and $\mathrm{S}$ $\mathrm{A}_{\mathrm{L}} \mathrm{PEI}$ on the most representative wavenumber ranges, while Figure AM4a-c shows the FTIR spectra for the sorbent before and after metal sorption, after metal desorption and after five successive cycles of sorption and desorption. The composition of the $\mathrm{A}_{\mathrm{L}} \mathrm{PEI}$ sorbent (algal biomass, PEI) and the mode of fabrication (calcium carbonate used for alginate extraction) may explain the diversity of reactive groups appearing on the spectrum of the raw material. More specifically, $-\mathrm{NH}$, $-\mathrm{OH},-\mathrm{COOH}$ and quaternary $\mathrm{N}$ groups can be identified (Table AM4), in addition to residual carbonate. The sulfonation of the raw beads induces substantial changes associated with the appearance of a series of new bonds, including C-S, O-S, $-\mathrm{SO}_{3} \mathrm{H}$ and $\mathrm{SO}_{4}{ }^{2-}$, while other signals disappear being involved in grafting mechanism $\left(-\mathrm{OH}\right.$ at $\left.686 \mathrm{~cm}^{-1}\right)$ or being affected by experimental conditions (disappearance of carbonate signals at $1417 \mathrm{~cm}^{-1}$ and $873 \mathrm{~cm}^{-1}$ ).

The broad band between $3600 \mathrm{~cm}^{-1}$ and $3250 \mathrm{~cm}^{-1}$ corresponds to the overlap of $-\mathrm{NH}$ and $-\mathrm{OH}$ stretching vibrations $[58,59]$. This signal is poorly affected by the sulfonation of the raw material. On the opposite hand, after metal sorption (regardless of the metal), the FWHM (full width at half maximum) appears to be increased, while after desorption (or after the cycles of sorption and desorption) the signal tends to be restored. This means that $-\mathrm{NH}$ and/or $-\mathrm{OH}$ groups are probably involved in metal binding.

The peaks in the range $2990-2850 \mathrm{~cm}^{-1}$ correspond to asymmetric C-H stretch and symmetric stretching vibrations of aliphatic methyl and methylene groups [60]; these groups are poorly reactive and they are not affected significantly by neither sorbent sulfonation nor metal sorption.

A new band appears at $1736 \mathrm{~cm}^{-1}$; this band is assigned to $\mathrm{C}=\mathrm{O}$ ester (present on sulfosuccinic acid) and confirms the successful grafting of sulfonic-based compound [48]. The peaks at $1623 \mathrm{~cm}^{-1}$ (for $\mathrm{A}_{\mathrm{L}} \mathrm{PEI}$ ) and $1632 \mathrm{~cm}^{-1}$ (for S-ALPEI) correspond to the overlap of $\mathrm{C}=\mathrm{O}$ of amide groups [60]. 
The sulfonation of $A_{L} P E I$ is followed by the appearance of a wide band (multi peaks) centered at around $1513 \mathrm{~cm}^{-1}$, which is assigned to the overlapping of the stretching of $-\mathrm{C}=\mathrm{N}$ - opening with $-\mathrm{NH}$ signal from primary and secondary amine bending vibrations: these amine groups are involved in sulfosuccinic acid grafting. After metal sorption, this band is slightly shifted or disappears. After metal elution and after 5 successive cycles of sorption and desorption, this wide multi-band reappears; this confirms that these groups are involved in metal binding and that the sorbent is efficiently regenerated after metal desorption. The peak at $1385 \mathrm{~cm}^{-1}$ (for $A_{L} P E I$ ) and $1382 \mathrm{~cm}^{-1}$ (for $S-A_{L} P E I$ ) is usually assigned to $\mathrm{N}^{+}$[46] that forms ionic bonds with carboxylate or carbonate in $\mathrm{A}_{\mathrm{L}} \mathrm{PEI}$ or with sulfate in $\mathrm{S}-\mathrm{A}_{\mathrm{L}} \mathrm{PEI}$.

A series of peaks (at $1138 \mathrm{~cm}^{-1}$ and $1227 \mathrm{~cm}^{-1}$ ) are assigned to -OH vibration (and associated with sulfosuccinic acid grafting). The sulfonation is also clearly identified by the appearance of the peak at $832-813 \mathrm{~cm}^{-1}$, which is assigned to C-O-S stretching vibration $[61,62]$, and the appearance of a new peak at $518 \mathrm{~cm}^{-1}$, attributed to $\mathrm{C}-\mathrm{S}$ bond [62].

Sulfonation probably involves interactions with both $-\mathrm{OH}$ and $-\mathrm{NH}$ groups. The interactions of REEs with $S-\mathrm{A}_{\mathrm{L}} \mathrm{PEI}$ are characterized by (a) the relative decrease in intensities of the peaks associated with $\mathrm{SO}_{3} \mathrm{H}$, $\mathrm{OH}, \mathrm{NH}$ and $\mathrm{COO}^{-}$functional groups (Figure AM4), and (b) the small shifts in their relevant bands (Table AM5). This means that the binding of REEs may involve numerous types of different bonds. The figures also show that the modifications of the spectra are reversible during metal desorption: the main bands are restored. This confirms both the efficient desorption of the metals and the stability of the reactive groups. This stability of the sorbent is also demonstrated by the remarkable stability of the FTIR spectra after the sorbent was submitted to five successive cycles of sorption and desorption (Figure AM4 and Tables AM4 and AM5).

\subsubsection{XPS spectroscopy}

Fig. 1 compares the XPS survey spectra of $A_{L} P E I$, and S- $A_{L} P E I$ (before and after metal sorption from multi-component solutions). The grafting of sulfonic groups is logically associated to the appearance of a new band at binding energy $(B E) \approx 168.5-169 \mathrm{eV}$, assigned to $\mathrm{S} 2 \mathrm{p}$ signal [63], while the intensity of Ca $2 p$ signal strongly decreases. The experimental procedure for the grafting of sulfonic groups involves the ion exchange of $\mathrm{Ca}(\mathrm{II})$ with protons. The effective binding of REEs on S$\mathrm{A}_{\mathrm{L}} \mathrm{PEI}$ is confirmed by the presence of most significant signals: Sc $2 \mathrm{p}$ at $\approx 399-400 \mathrm{eV}$, Ce $4 \mathrm{~s}$ at $289.7 \mathrm{eV}$, and $\mathrm{Ho} 4 \mathrm{~d}$ at $163.3 \mathrm{eV}$. It is noteworthy that these peaks are very close to other bands for N 1s, C 1s and $S$ 2p, respectively.
Figure AM5 shows the high-resolution XPS spectra (HRES) of selected signals for $A_{L} P E I, S-A_{L} P E I$ and REE-loaded sorbent. The functionalization of $\mathrm{A}_{\mathrm{L}} \mathrm{PEI}$ is followed by the significant increase of the intensity of the band at $400.6 \mathrm{eV}$ that corresponds to tertiary amine, and the formation of a small band assigned to quaternary ammonium salt at $402.15 \mathrm{eV}$ [64]. After the sorption of REEs, the intensity of tertiary amine decreases while the band assigned to quaternary ammonium is shifted to $401.6 \mathrm{eV}$, with a significant increase of its intensity. This observation confirms the contribution of amine groups in the binding of REEs onto $S-A_{L} P E I$. The HRES spectrum for $O$ 1s signal is also affected by the changes brought to the sorbent. On $A_{L}$ PEI, the main peak is detected at $530.75 \mathrm{eV}$ (assigned to $\mathrm{O}$ bonds with $\mathrm{N}, \mathrm{C}$ and $\mathrm{H}$ elements); the second deconvolution peak is observed at $532.3 \mathrm{eV}$. After sulfonation, the spectrum is marked by the shift (and the decrease in intensity) of the main peak to $531.4 \mathrm{eV}$, while the intensity of the band at $532.15 \mathrm{eV}$ is increased, probably due to the formation of new O-S bonds. After REE sorption, the HRES spectrum is poorly changed, the shoulder on the composite spectrum at $\sim 532 \mathrm{eV}$ is apparently widened and little increased. More interesting are the observations associated with S 2p band. A flat and poorly resolved band appears at $167.75 \mathrm{eV}$ (which may represent the convolution of the two components $S 2 p_{1 / 2}$ and $S 2 p_{3 / 2}$, [65]) on $A_{L}$ PEI spectrum; the weak content of $S$ (see below) provided by fucoidan into algal biomass may explain the weak intensity of the signal. Obviously, the sulfonation of the sorbent increases the density of $S$ groups making the $S 2$ p spectrum more exploitable. An intense and broad band is observed at $167.75 \mathrm{eV}$ (convolution of the spin-orbit components for oxidized form of S) ; the band is asymmetric due to the presence of sulfate (with much lower intensity) identified by two peaks at $168.25 \mathrm{eV}$ and $169.05 \mathrm{eV}$ [66]. After REE sorption, the intensities of sulfate peaks tend to decrease (associated with a little shift). Therefore, the broad peak (convolution of spin-orbit components for main S signal) is shifted to $167.55 \mathrm{eV}$ and it becomes symmetric. It is another confirmation of the contribution of sulfonic groups in the binding of REEs.

\subsubsection{Elemental analysis}

Table 1 shows the elemental analysis of both $A_{L}$ PEI and S-A $A_{L}$ PEI. The efficient sulfonation is demonstrated by the increase in $\mathrm{O}$ and $\mathrm{S}$ contents. $\mathrm{A}_{\mathrm{L}} \mathrm{PEI}$ beads naturally contains sulfur due to the presence of fucoidan in the wall of $L$. digitata [67 68]; however, the biopolymer fraction (which depends on seasonal variations, part of the algae, collect location, etc.) remains very low in the raw support [69]. The functionalization of the beads increased the content from $0.32 \%$ (i.e., $0.100 \mathrm{mmol} \mathrm{S} \mathrm{g}^{-1}$ ) to $3.08 \%$ (i.e., $0.961 \mathrm{mmol} \mathrm{S} \mathrm{g}^{-1}$ ). The grafting of

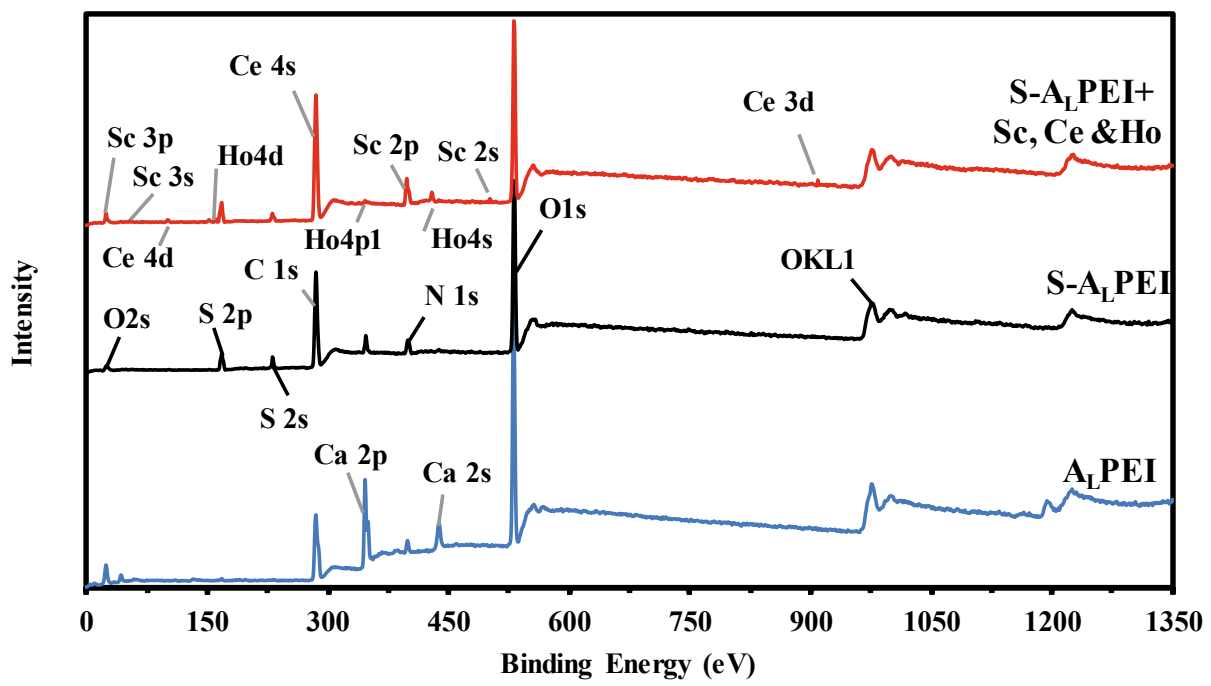

Fig. 1. XPS survey spectra of $A_{L} P E I, S-A_{L} P E I$, and $S-A_{L} P E I$ after binding of Sc(III), Ce(III) and Ho(III) (multi-component solution). 
Table 1

Elemental analysis of sorbents (wt. \%, and molar units for $\mathrm{N}$ and S elements).

\begin{tabular}{llllllll} 
Sorbent & $\mathrm{C}(\%)$ & $\mathrm{H}(\%)$ & $\mathrm{O}(\%)$ & $\mathrm{N}(\%)$ & $\mathrm{N}\left(\mathrm{mmol} \mathrm{g}^{-1}\right)$ & $\mathrm{S}(\%)$ & $\mathrm{S}\left(\mathrm{mmol} \mathrm{g}^{-1}\right)$ \\
\hline $\mathrm{A}_{\mathrm{L}} \mathrm{PEI}$ & 35.77 & 12.86 & 35.06 & 2.46 & 1.756 & 0.27 & 0.084 \\
$\mathrm{~A}_{\mathrm{L}} \mathrm{PEI}$ & 44.52 & 12.89 & 37.94 & 2.59 & 1.849 & 0.32 & 0.010 \\
${\mathrm{~S}-\mathrm{A}_{\mathrm{L}} \mathrm{PEI}}^{\mathrm{R}}$ & 38.85 & 14.99 & 40.32 & 2.41 & 1.721 & 3.08 & 0.961
\end{tabular}

$\mathrm{A}_{\mathrm{L}} \mathrm{PEI}^{\mathrm{R}}: \mathrm{A}_{\mathrm{L}} \mathrm{PEI}$ beads before extensive washing.

$-\mathrm{SO}_{3}$ groups is also followed by an increase on $\mathrm{O}$ content (from 23.71 to $25.20 \mathrm{mmol} \mathrm{O} \mathrm{g}^{-1}$ ). It is noteworthy that the total of $\mathrm{C}, \mathrm{H}, \mathrm{O}, \mathrm{N}$ and $\mathrm{S}$ fractions reaches only $98.26 \%$. This means that other elements represent a non-negligible fraction of the sorbent. This is confirmed by EDX semi-quantitative analysis (Table AM6): traces of $\mathrm{Cl}$ element (ionotropic gelation of alginate chains) and $\mathrm{Na}$ element (extraction of alginate from algal biomass) are found. However, the most important impurity is Ca (final ionotropic gelation of the algal/PEI sorbent). The semi-quantitative analysis of the raw beads before extensive washing show a very high content of Ca (i.e., almost $18 \%$, wt.) that could explain the missing part in the elemental analysis of these beads (total CHONS percentage: $86.42 \%$ ). The washing of raw beads $\left(A_{L} P^{R}{ }^{R}\right)$ is a critical step in the production of $S-A_{L} P E I$. The SEM views demonstrates the roughness of the surface of the beads and the scaffold structure of the sorbent (apparent porosity) (Table AM6b). Table AM6c shows that the materials are heterogeneous while comparing the semi-quantitative analysis of the surfaces and the crosscut sections:

(a) in $A_{L}$ PEI: higher density of Ca (due to ionotropic gelation) and lower density of $\mathrm{N}$ on the external layers,

(b) in S- $\mathrm{A}_{\mathrm{L}} \mathrm{PEI}$ : higher sulfonation of the surface of the beads (decreased atomic percentage in the crosscut section).

The sulfonation of $\mathrm{A}_{\mathrm{L}} \mathrm{PEI}$ is followed by a substantial decrease of $\mathrm{Ca}$ (both at the surface and in the core of the beads), while the $\mathrm{O}$ content significantly increases (associated with $\mathrm{O}$ from sulfonate). It is noteworthy that the extensive washing of the raw beads removed a great amount of $\mathrm{Ca}$ (in excess during the ionotropic gelation step, Table AM6a).

\subsubsection{Surface charge - $p H_{P Z C}$}

Figure AM6 compares the $\mathrm{pH}$ variation for $\mathrm{A}_{\mathrm{L}} \mathrm{PEI}$ and $\mathrm{S}-\mathrm{A}_{\mathrm{L}} \mathrm{PEI}$ while applying the $\mathrm{pH}$-drift method for the determination of their $\mathrm{pH}_{\mathrm{PZC}}$ values. The functionalization of the $\mathrm{A}_{\mathrm{L}} \mathrm{PEI}$ strongly affects the acid-base properties of the material: the $\mathrm{pH}_{\mathrm{PZC}}$ decreases from 7.35 to 2.86 . This result demonstrates that the grafting of sulfonic groups on the sorbent is highly effective. This also means that the surface of $A_{L} P E I$ is positively charged on a large $\mathrm{pH}$ range, contrary to $\mathrm{S}-\mathrm{A}_{\mathrm{L}} \mathrm{PEI}$ : the sulfonate anionic groups predominate above $\mathrm{pH} 2.86$. The sorption of cationic species $\left(\mathrm{REE}^{3+}\right)$ by electrostatic attraction is strongly favored for $S-A_{L} \mathrm{PEI}$, while the electrostatic repulsion limits cation sorption on $A_{L}$ PEI. The sorption of metal cations on $\mathrm{A}_{\mathrm{L}} \mathrm{PEI}$ is thus expected to be limited to:

(a) chelation on free carboxylate groups from alginate $\left(\mathrm{pK}_{\mathrm{a}} \mathrm{s}\right.$ of carboxylic groups in mannuronic and guluronic acid: 3.38 and 3.65, respectively [70]) or free primary amine groups $\left(\mathrm{pK}_{\mathrm{a}} \mathrm{s}\right.$ of amine groups: 4.5 (primary), 6.7 (secondary) and 11.6 (tertiary) [71]), or

(b) ion-exchange with protonated groups (under the control of proton excess at low $\mathrm{pH}$ ).

Similar strong shift in $\mathrm{pH}_{\mathrm{PZC}}$ was reported for the sulfonation of agriculture wastes (hawthorn kernel) from 7 to 3.9 [56]. Urbano and Rivas [72] reported a $\mathrm{pH}_{\mathrm{PZC}}$ close to 3.4 for montmorillonite-polystyrene sulfonate/polyacrylamide glycolic acid composite.

\subsection{Sorption studies}

\subsection{1. $p H$ effect}

Fig. 2 compares the effect of $\mathrm{pH}$ on the sorption of Sc(III), Ce(III) and $\mathrm{Ho}(\mathrm{III})$ for $\mathrm{A}_{\mathrm{L}} \mathrm{PEI}$ and $S-\mathrm{A}_{\mathrm{L}} \mathrm{PEI}$. Regardless of the metal, the sorption capacity for $\mathrm{A}_{\mathrm{L}} \mathrm{PEI}$ progressively increases from $\mathrm{pH} 1$ to $\mathrm{pH}$ 5: from 0.01 to $0.04 \mathrm{mmol} \mathrm{g}^{-1}$ for $\mathrm{Ce}(\mathrm{III})$ and $\mathrm{Ho}(\mathrm{III})$, and from $0.05 \mathrm{mmol}$ to $0.2 \mathrm{mmol} \mathrm{g}^{-1}$ for $\mathrm{Sc}$ (III). For $\mathrm{A}_{\mathrm{L}} \mathrm{PEI}$, the sorption capacity is increased 4 times while increasing the $\mathrm{pH}$ and the sorption capacity is about 5 times higher for Sc(III) than for other REEs. Increasing the $\mathrm{pH}$ above 3.7 leads to the deprotonation of carboxylic groups (on the alginate fraction of the algal biomass) and reduces the protonation of free primary amines groups of PEI in the raw sorbent. This potentially enhances the binding of REEs on these two types of reactive groups. In the case of $S-A_{L} P E I$, the beneficial effect of $\mathrm{pH}$ is even increased, especially for $\mathrm{Sc}(\mathrm{III})$ and $\mathrm{Ce}$ (III). Between $\mathrm{pH} 1$ and 1.75, the sorption capacity remains close to $0.12 \mathrm{mmol} \mathrm{Sc}^{-1}$ (0.05 $\mathrm{mmol} \mathrm{g}^{-1}$ for Ce(III) and Ho(III)), before increasing up to 0.2 mmol $\mathrm{Ho}^{-1}$ at $\mathrm{pH} 4$ (comparable with $\mathrm{A}_{\mathrm{L}} \mathrm{PEI}$ ), $0.3 \mathrm{mmol} \mathrm{Ce}^{-1}$ (little more than $\mathrm{A}_{\mathrm{L}} \mathrm{PEI}$ ). For Sc(III), the improvement in sorption capacity is strongly increased, up to $1.2 \mathrm{mmol} \mathrm{Sc}^{-1}$ (six times) after sulfonation. Actually, the strong increase in sorption capacities occurs when $\mathrm{pH}>\mathrm{pH}_{\mathrm{PZC}}$.

Figure AM7 shows the speciation diagrams for Ho(III), Ce(III) and $\mathrm{Sc}(\mathrm{III})$ under the experimental conditions used for the study of $\mathrm{pH}$
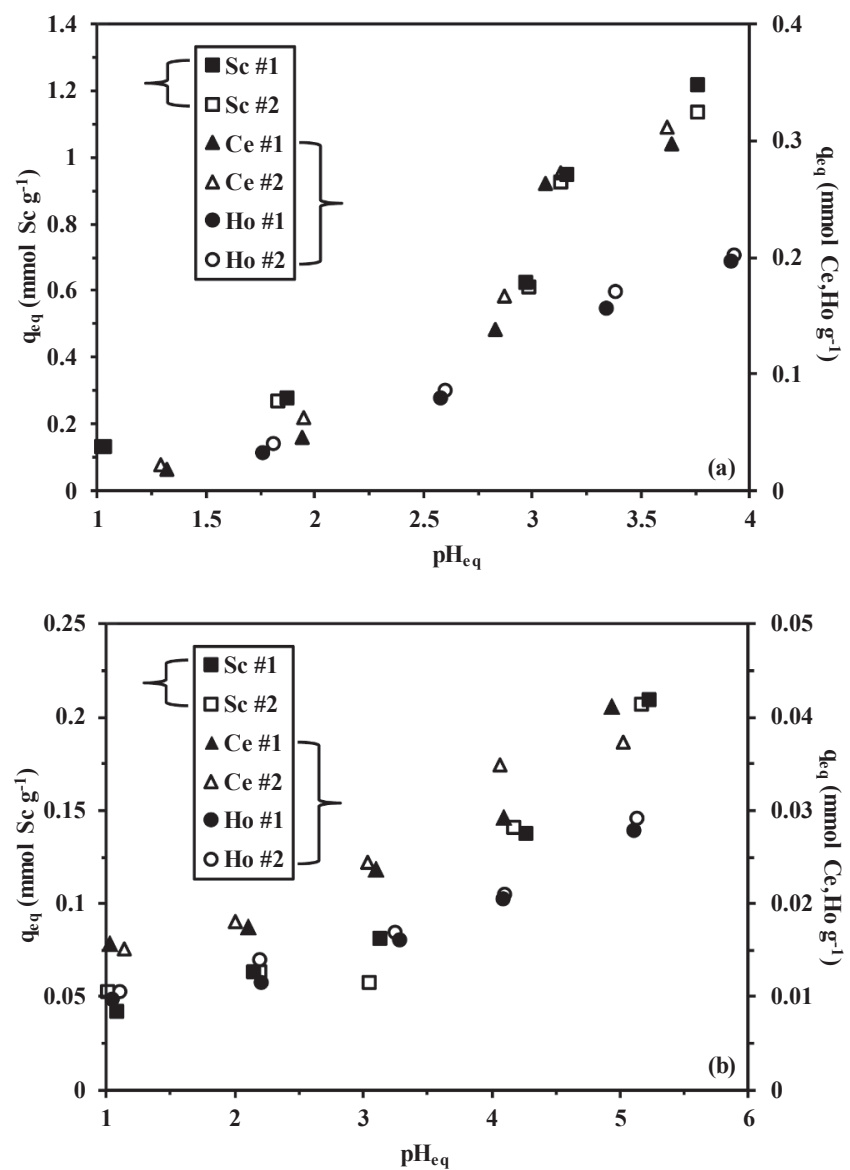

Fig. 2. Effect of pH on REE(III) sorption using $S-A_{L} P E I$ (a) and $A_{L} P E I$ (b) $\left(C_{0}\right.$ : $100 \mathrm{mg} \mathrm{L}^{-1}$; or $2.3 \mathrm{mmol} \mathrm{Sc} \mathrm{L}^{-1}, 0.72 \mathrm{mmol} \mathrm{Ce} \mathrm{L}^{-1}, 0.65 \mathrm{mmol} \mathrm{Ho} \mathrm{L}^{-1}$; Sorbent dosage, SD: $166 \mathrm{mg} \mathrm{L}^{-1}$; contact time: $48 \mathrm{~h}$; T: $22 \pm 2{ }^{\circ} \mathrm{C}$; agitation speed: $170 \mathrm{rpm})$. 
effect. Holmium and cerium follow very close species distribution with predominance of monovalent cationic sulfate species (i.e., $\mathrm{HoSO}_{4}{ }^{+}$and $\mathrm{CeSO}_{4}{ }^{+}$) at $\mathrm{pH} 1-2$; the fraction of free $\mathrm{REE}^{3+}$ progressively increases (and tends to approach the fraction of metal sulfate), while other species are negligible. In the case of $\mathrm{Sc}(\mathrm{III})$, the fraction of $\mathrm{ScSO}_{4}{ }^{+}$remains higher than $75 \%$ in the $\mathrm{pH}$ range $1-4.2$; other species are essentially represented in acidic region by the anionic species $\left(\mathrm{Sc}_{\mathrm{CO}} \mathrm{SO}_{4}\right)^{2-}$, in very acidic solutions) and free $\mathrm{Sc}^{3+}$ species. The coexistence of monovalent and trivalent cationic species makes complex in the interpretation of sorption mechanism. For scandium, the large predominance of the monovalent sulfate cation on the whole $\mathrm{pH}$ range of the study (i.e., $\mathrm{pH}$ 4) may explain the higher sorption compared with other REEs.

The distribution coefficient (defined as $\left.\mathrm{D}\left(\mathrm{L} \mathrm{g}^{-1}\right)=\mathrm{q}_{\mathrm{eq}} / \mathrm{C}_{\mathrm{eq}}\right)$ increases linearly, in log units, with pH (Figure AM8): the slope, which corresponds to the stoichiometric of proton exchange in ion-exchange processes, varies between 0.12 for Ce(III) and Ho(III) and 0.17 for Sc (III) in the case of $A_{L} P E I$. In the case of $S-A_{L} P E I$, higher slopes are reported: +0.43 for $\mathrm{Ho}(\mathrm{III}),+0.62$ for $\mathrm{Sc}(\mathrm{III})$ and +0.75 for $\mathrm{Ce}(\mathrm{III})$. These slopes are linearly correlated with the electronegativity of these metal ions in water $\left(\chi_{\mathrm{aq}}\right)$ (Table AM7, [73]): slope $=2.57-0.63 \chi_{\mathrm{aq}}$ $\left(\mathrm{R}_{2}: 0.985\right)$. This higher sensitivity to $\mathrm{pH}$ is directly correlated to the grafting of anionic sulfonic groups. This is also confirmed by Figure AM9 that summarizes the $\mathrm{pH}$ variation during metal sorption for the two systems. The $\mathrm{pH}$ remains remarkably stable with $\mathrm{A}_{\mathrm{L}} \mathrm{PEI}$ : the variation does not exceed $0.3 \mathrm{pH}$ unit. The $\mathrm{pH}$ variations are significantly more marked with S- $\mathrm{A}_{\mathrm{L}} \mathrm{PEI}$ : by less than 0.5 units between $\mathrm{pH}_{0} 1$ and 3 , and by $0.5-1 \mathrm{pH}$ unit at $\mathrm{pH}_{0} 4$ and 5 . These $\mathrm{pH}$ variations are consistent with the $\Delta \mathrm{pH}$ values reported with metal-free solutions (during $\mathrm{pH}_{\mathrm{PZC}}$ determinations), and with the ion-exchange properties reinforced by the grating of strong cation exchanger groups.

In the case of $\mathrm{Ce}(\mathrm{III})$ ion-exchange with the sulfonic-bearing commercial resin Dowex $50 \mathrm{~W}$ X8, Miller et al. [36] discuss the binding mechanism through the comparison of the effect of counter-anions (more specifically sulfate $v s$. nitrate anions). They suggested that the sorption process consists of three steps: (a) hydration of $\mathrm{H}^{+}$in the resin, (b) ion interaction of the counter anion bound to REE with the ionic sites $\mathrm{H}_{3} \mathrm{O}^{+}$, followed by (c) the ion-exchange of $\mathrm{H}_{3} \mathrm{O}^{+}$and $\mathrm{REE}^{3+}$. Sorption of cerium in sulfate media is enhanced by $15 \%$ compared with nitrate media; they explained this difference by the change in the coordination mode: $\mathrm{Ce}^{3+} / \mathrm{SO}_{4}{ }^{2-}$ coordinates to two $\mathrm{R}-\mathrm{SO}_{3}{ }^{-}$sites contrary to $\mathrm{Ce}^{3+} / \mathrm{NO}_{3}{ }^{-}$that requires three $\mathrm{R}-\mathrm{SO}_{3}{ }^{-}$sites. It is supposed that similar reasons may explain the differences in the sorption capacities for $\mathrm{Sc}$ (III) (almost exclusively present as sulfate species) against Ho(III) and Ce (III) (which only forms sulfate species in acidic solutions, with increasing fraction of free $\mathrm{REE}^{3+}$ when $\mathrm{pH}$ increases).

\subsubsection{Uptake kinetics}

Under selected experimental conditions (especially sorption dosage and range of metal concentration), the equilibrium is reached within 20-40 min, depending on the metal (Figs. 3a-c). The superimposition of the curves show that the sorption performances are reproducible. While increasing metal concentration, the time required to reach the equilibrium slightly decreases: the higher external concentration leads to higher driving force, faster saturation of the reactive groups at the surface of the sorbent and earlier equilibrium between the solid and liquid phases. The large mesoporosity of the sorbent can explain the relatively fast mass transfer observed with $S$ - $A_{L} P E I$. The mass transfer may be controlled by resistances to film diffusion and to intraparticle diffusion, in addition to the proper reaction rate (which may be modeled using the pseudo-first order, PFORE, or the pseudo-second order rate equation, PSORE). PFORE is usually associated with physical sorption, while the PSORE is supposed to correspond to a chemical sorption mechanism. Recently, Hubbe et al. [74] discussed the limitations associated to pseudo-second order rate equation: first, they pointed out the misuse of this equation when appropriate experimental conditions are not applied (especially, the limited variation of the concentration of the solute in the solution). They also concluded that, in many cases, the PSORE selection is inferred to a control of mass transfer by resistance to intraparticle diffusion. Simonin [75] also pointed out the critical impact of the selection of experimental procedures (including the distribution of experimental points) on the relative quality of PFORE and PSORE fits, which, in turn, influences the appropriateness of selection criteria. It is thus important keeping a critical eye on the conclusions raised while comparing statistical fits.

The different equations summarized on Table AM2 were used for fitting kinetic profiles (using non-linear regression analysis); Tables 2a$c$ reports the values of the parameters for the different REEs and for different metal concentrations. The values of the determination coefficients $\left(\mathrm{R}^{2}\right)$ and the comparison of the calculated and experimental values for the sorption capacity at equilibrium $\left(\mathrm{C}(\mathrm{t})_{\text {fitted }} / \mathrm{C}_{0}\right.$ vs. $\left.\mathrm{C}(\mathrm{t})_{\exp } / \mathrm{C}_{0}\right)$ demonstrate that the pseudo-first order rate equation is more
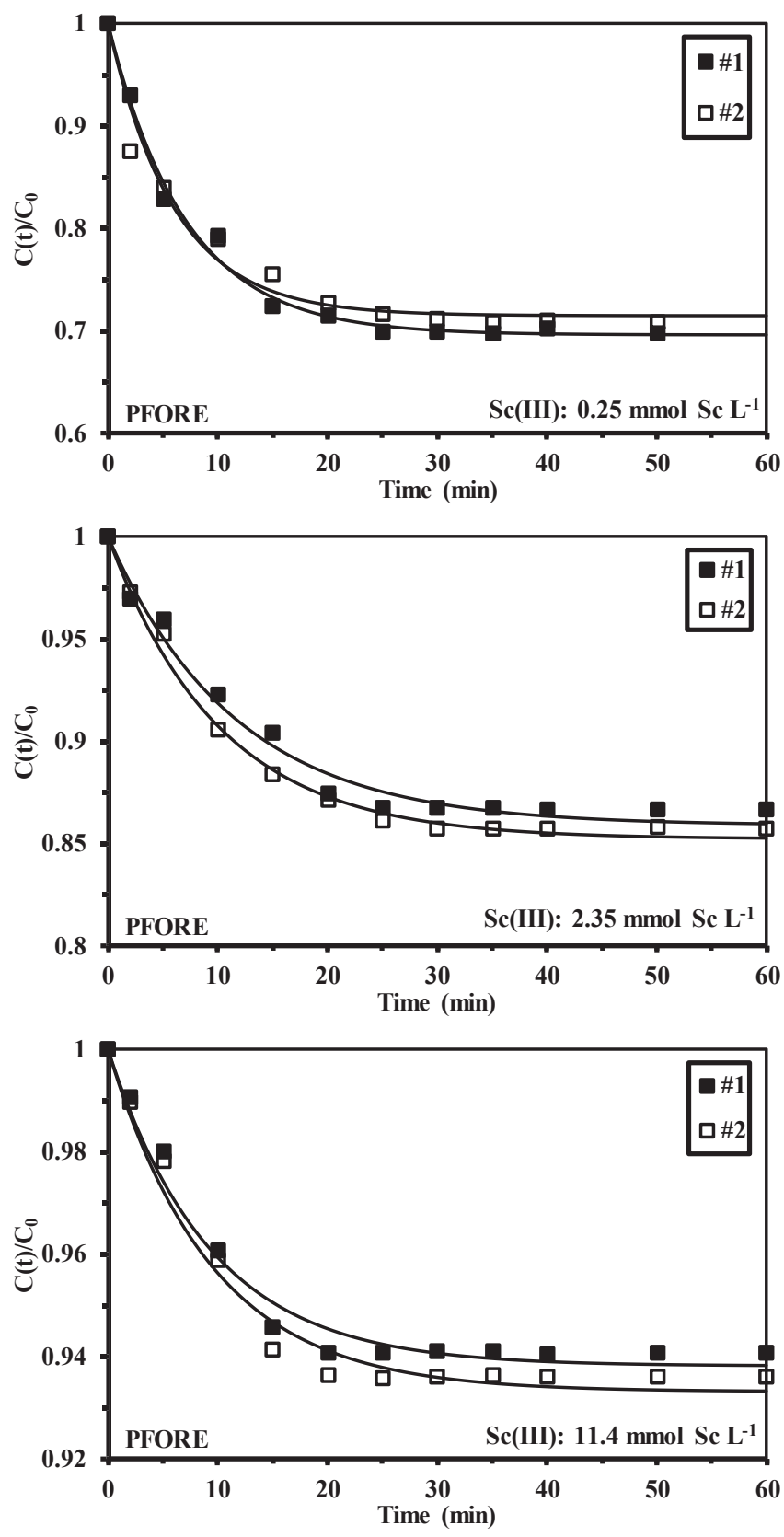

Fig. 3a. Sc(III) uptake kinetics at $\mathrm{pH}_{0} 5$ using S- $\mathrm{A}_{\mathrm{L}} \mathrm{PEI}-$ Modeling with the PFORE ( $\mathrm{C}_{0}$ : 0.25, 2.35 and $11.4 \mathrm{mmol} \mathrm{Sc} \mathrm{L}^{-1}$; SD: $0.25 \mathrm{~g} \mathrm{~L}^{-1}$; $\mathrm{pH}_{\mathrm{eq}}: 3.8-3.4$; $\mathrm{T}$ : $22 \pm 2{ }^{\circ} \mathrm{C}$; agitation speed: $170 \mathrm{rpm}$ ). 

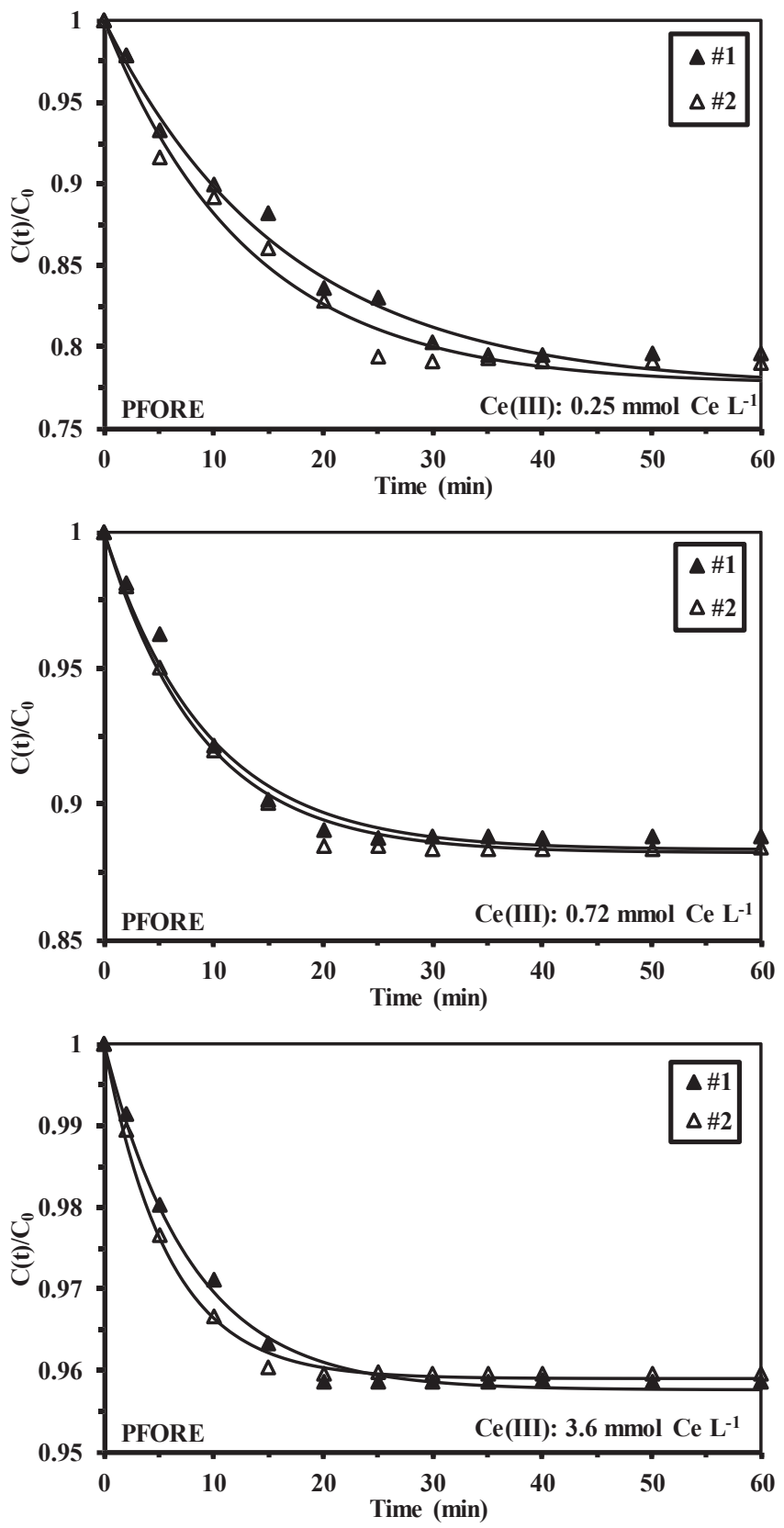

Fig. 3b. $\mathrm{Ce}(\mathrm{III})$ uptake kinetics at $\mathrm{pH}_{0} 5$ using S- $\mathrm{A}_{\mathrm{L}} \mathrm{PEI}-$ Modeling with the

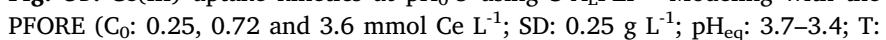
$22 \pm 2{ }^{\circ} \mathrm{C}$; agitation speed: $\left.170 \mathrm{rpm}\right)$.

appropriate for modeling the kinetic profiles. The sorption rate is proportional to the number of free sorption sites at the surface of the sorbent. This is generally confirmed by the AIC values; in most cases, the lowest (negative) AIC values are obtained for the PFORE.

As expected, increasing metal concentration increases the sorption capacity at equilibrium. The ranges of concentrations have been selected for describing different levels of saturation of the sorbent. The quality of the fit increases with metal concentration (and sorbent saturation). The apparent rate coefficient $\left(\mathrm{k}_{1}\right)$ does not show a clear evolution with metal concentration. However, it is possible observing that $\mathrm{k}_{1}$ varies according:

(a) for Sc(III) between $8.6 \times 10^{-2} \mathrm{~min}^{-1}$ and $16.5 \times 10^{-2} \mathrm{~min}^{-1}$,

(b) for Ce(III) between $6.0 \times 10^{-2} \mathrm{~min}^{-1}$ and $17.1 \times 10^{-2} \mathrm{~min}^{-1}$, and

(c) for Ho(III) between $6.1 \times 10^{-2} \mathrm{~min}^{-1}$ and $13.0 \times 10^{-2} \mathrm{~min}^{-1}$.
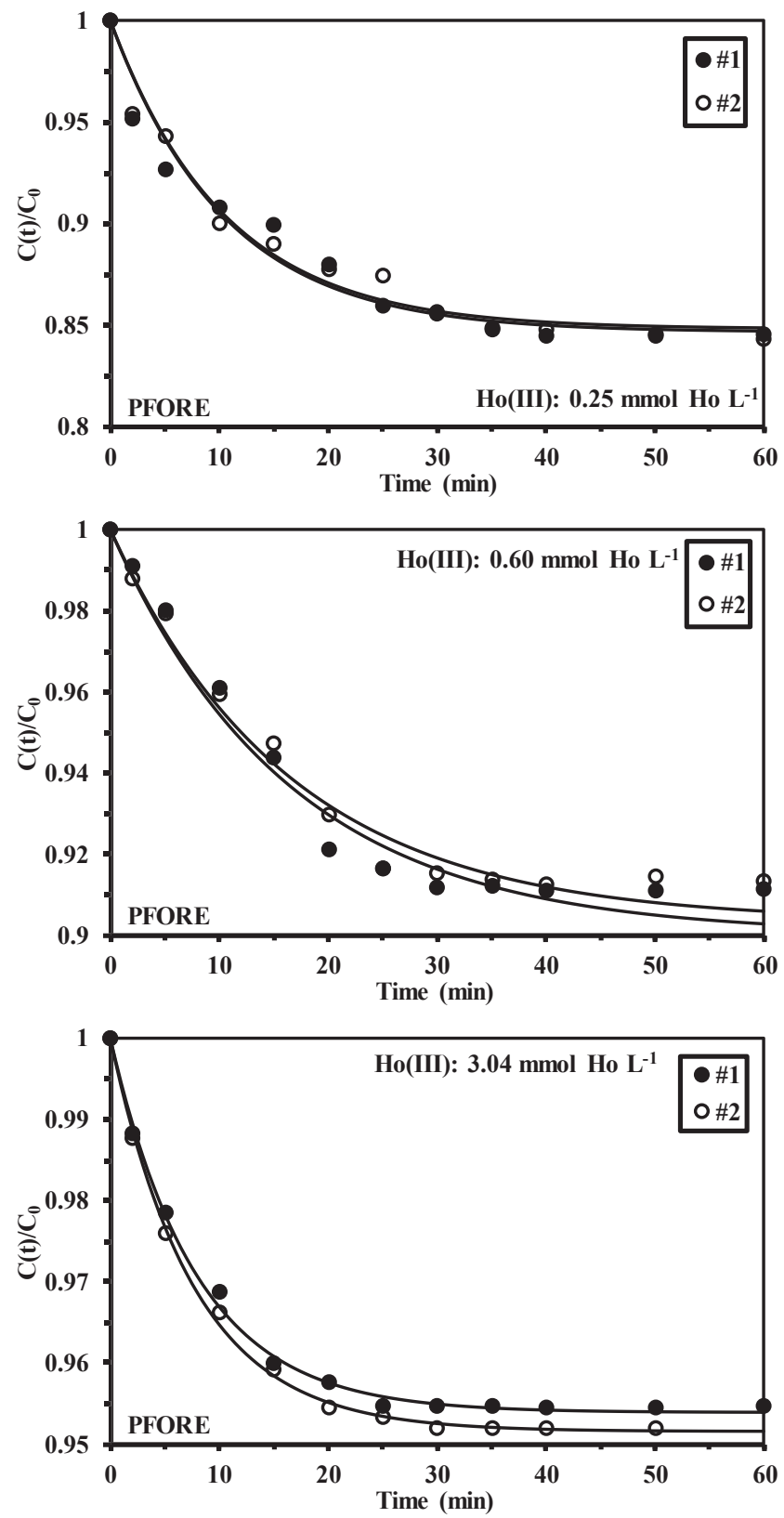

Fig. 3c. Ho(III) uptake kinetics at $\mathrm{pH}_{0} 5$ using $\mathrm{S}-\mathrm{A}_{\mathrm{L}} \mathrm{PEI}-$ Modeling with the PFORE $\left(\mathrm{C}_{0}\right.$ : $0.60 \mathrm{mmol} \mathrm{Ho} \mathrm{L}^{-1}$ and $3.04 \mathrm{mmol} \mathrm{Ho} \mathrm{L}^{-1}$; SD: $0.25 \mathrm{~g} \mathrm{~L}^{-1}$; $\mathrm{pH}_{\mathrm{eq}}$ : 3.9-3.7; T: $22 \pm 2{ }^{\circ} \mathrm{C}$; agitation speed: $170 \mathrm{rpm}$ ).

This means that the uptake kinetics for the three REEs are very similar: the separation of the three metal ions cannot be operated through kinetic-based process. This is confirmed by the comparison of the effective diffusivity coefficients: $1.47-1.82 \times 10^{-8} \mathrm{~m}^{2} \mathrm{~min}^{-1}$ for Sc (III), $1.04-2.76 \times 10^{-8} \mathrm{~m}^{2} \mathrm{~min}^{-1}$ for Ce(III) and $1.15-2.07 \times 10^{-8} \mathrm{~m}^{2}$ $\min ^{-1}$ for Ho(III). The effective diffusivities are of the same order of magnitude for the three REEs and very close from their molecular diffusivity in water (i.e., $3.44 \times 10^{-8} \mathrm{~m}^{2} \mathrm{~min}^{-1}$ for Sc(III), $1.04 \times 10^{-8} \mathrm{~m}^{2}$ $\min ^{-1}$ for Ce(III) and $1.15 \times 10^{-8} \mathrm{~m}^{2} \mathrm{~min}^{-1}$ for Ho(III)). These values confirm that the large mesoporosity of the sorbents limits the effect of the resistance to intraparticle diffusion and that the kinetic profiles are essentially controlled by the proper reaction rate (i.e., PFORE). The three REEs have very close behaviors. In order to evaluate their intrinsic specificities, uptake kinetics were also performed with multicomponent solutions (containing the same mass concentration; i.e., $100 \mathrm{mg}$ metal $\mathrm{L}^{-1}$ of each REE, Fig. 4a, and at equimolar molar 

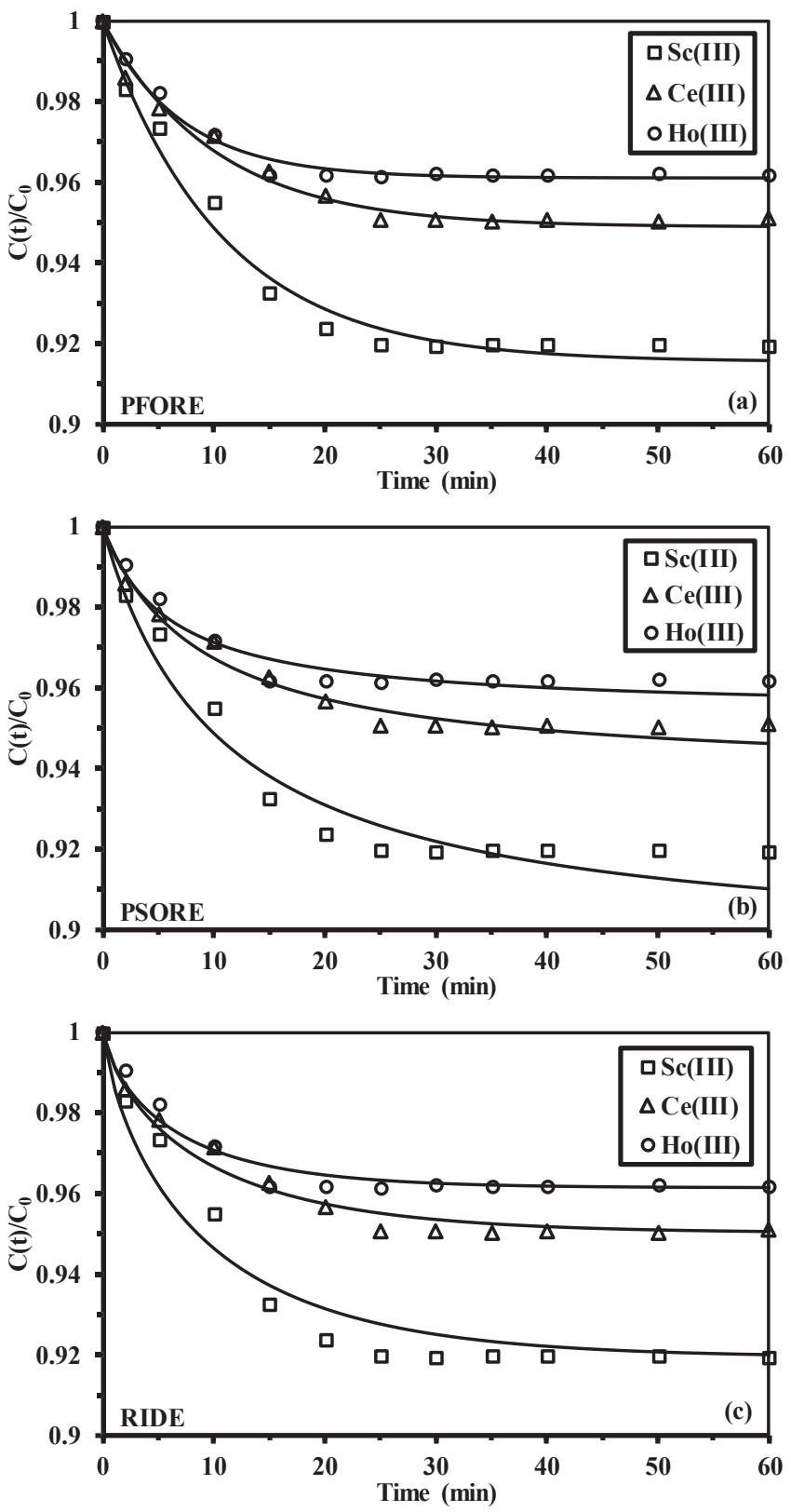

Fig. 4a. Uptake kinetics for multi-component solutions at $\mathrm{pH}_{0} 5$ using S-A $\mathrm{A} \mathrm{PEI}-$ Modeling with the PFORE, PSORE and RIDE $\left(\mathrm{C}_{0}: 100 \mathrm{mg} \mathrm{L}^{-1}\right.$; SD: $0.25 \mathrm{~g} \mathrm{~L}^{-1}$; $\mathrm{pH}_{\mathrm{eq}}$ : 3.6; T: $22 \pm 2{ }^{\circ} \mathrm{C}$; agitation speed: $\left.170 \mathrm{rpm}\right)$.

concentrations; i.e., $0.25 \mathrm{mmol}$ metal $\mathrm{L}^{-1}$, Fig. 4b). From Fig. 4b, it seems that cerium requires a little longer contact time for reaching the equilibrium. The values of apparent rate coefficient for PFORE (i.e., $\mathrm{k}_{1}$ ) and the effective diffusivity coefficient are of the same order of magnitude than for mono-component solutions. Table $2 \mathrm{~d}$-e confirms that the mass transfer rates can be ranked according: $\mathrm{Ho}(\mathrm{III})>\mathrm{Sc}(\mathrm{III})>$ Ce(III). This ranking cannot be correlated to ionic radius of REEs: Ce (III) $(1.196 \AA)>\mathrm{Ho}(\mathrm{III})(1.015 \AA)>\mathrm{Sc}(\mathrm{IIII})(0.87 \AA)$, nor their molecular diffusivity $\left(\times 10^{-8} \mathrm{~m}^{2} \mathrm{~min}^{-1}\right)$ in water: $\mathrm{Ce}(\mathrm{III})(3.72)>\mathrm{Ho}$ (III) (3.53) $>\mathrm{Sc}$ (IIII) (3.44). Based on the large size of mesopores, the steric hindrance and the resistance to intraparticle diffusion are not controlling the mass transfer of REEs.

\subsubsection{Sorption isotherms}

The sorption isotherms are plotted on Fig. 5 for Sc(III), Ce(III) and $\mathrm{Ho}(\mathrm{III})$ removal from mono-component solutions at initial $\mathrm{pH} 5$ (equilibrium pH: 3.4-3.9) using S-A $\mathrm{L}$ PEI. As a comparison, Figure AM10
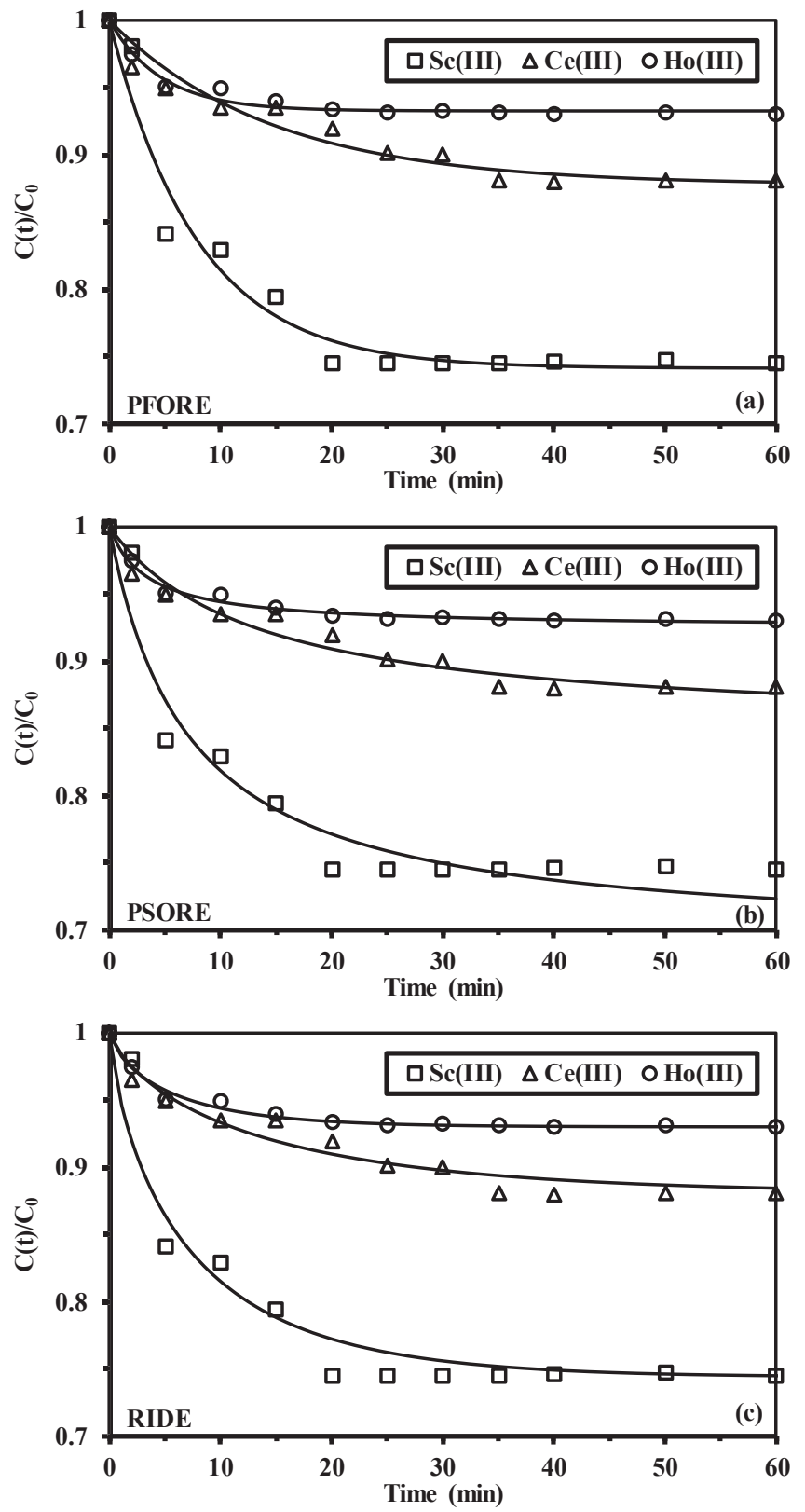

Fig. 4b. Uptake kinetics for multi-component solutions at $\mathrm{pH}_{0} 5$ using $\mathrm{S}-\mathrm{A}_{\mathrm{L}} \mathrm{PEI}-$ Modeling with the PFORE, PSORE and RIDE (C $0.25 \mathrm{mM}$; SD: $0.25 \mathrm{~g} \mathrm{~L}^{-1} ; \mathrm{pH}_{\mathrm{eq}}$ : 3.6; $\mathrm{T}: 22 \pm 2{ }^{\circ} \mathrm{C}$; agitation speed: $170 \mathrm{rpm}$ ).

shows the sorption isotherms for $\mathrm{A}_{\mathrm{L}} \mathrm{PEI}$ under similar conditions. The different curves are characterized by a weak initial slope; the progressive increase in sorption capacity tends to a saturation plateau, reached for a residual metal concentration close to $2-3 \mathrm{mmol}_{\text {metal L }}^{-1}$ for Ce(III) and Ho(III) and up to $7 \mathrm{mmol} \mathrm{Sc} \mathrm{L}^{-1}$ for Sc(III), in the case of $S-A_{L}$ PEI. The weak slopes mean that the sorbent has weak affinity for target metal ions. The saturation plateau is significantly higher for scandium (i.e., $2.61 \mathrm{mmol} \mathrm{Sc}^{-1}$ ) than for cerium (i.e., $0.61 \mathrm{mmol} \mathrm{Ce}$ $\mathrm{g}^{-1}$ ) and holmium (i.e., $0.53 \mathrm{mmol} \mathrm{Ho} \mathrm{g}^{-1}$ ). This is consistent with the results commented on the influence of $\mathrm{pH}$. Table AM7 reports a series of physicochemical parameters and it is not possible finding a clear correlation between their variations and the maximum sorption capacities. The sorption properties are probably more controlled by the differences in the speciation behavior of the three REEs. For $\mathrm{A}_{\mathrm{L}} \mathrm{PEI}$, the sorption isotherms follow the same trend with saturation plateaus at much lower sorption capacities: $0.077 \mathrm{mmol} \mathrm{Ho} \mathrm{g}^{-1}, 0.12 \mathrm{mmol} \mathrm{Ce} \mathrm{g}^{-1}$ and 

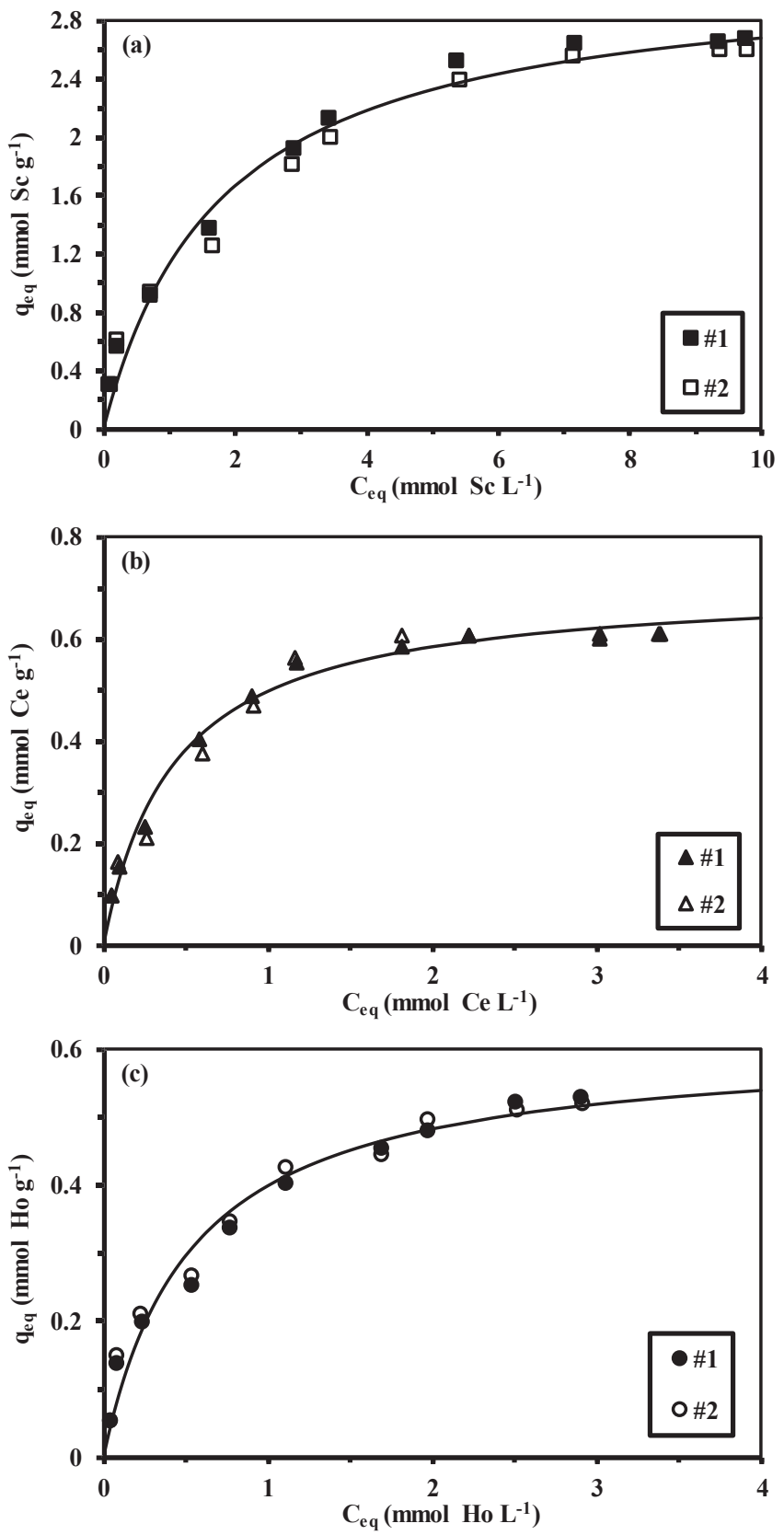

Fig. 5. Sorption isotherms for Sc(III) (a), Ce(III) (b) and Ho(III) (c) using S$\mathrm{A}_{\mathrm{L}} \mathrm{PEI}$ at $\mathrm{pH}_{0} 5$ - modeling with the Langmuir equation (solid lines; duplicates, Langmuir data calculated from cumulative curves; $\mathrm{SD}: 0.5 \mathrm{~g} \mathrm{~L}^{-1}$; $\mathrm{pH}_{\mathrm{eq}}$ : 3.9-3.4; T: $22 \pm 2{ }^{\circ} \mathrm{C}$; contact time: $48 \mathrm{~h}$; agitation speed: $170 \mathrm{rpm}$ ).

$0.37 \mathrm{mmol} \mathrm{Sc}^{-1}$. It is noteworthy that for $\mathrm{A}_{\mathrm{L}} \mathrm{PEI}$ the saturation plateau was not systematically reached in the range of concentrations investigated for S- $\mathrm{A}_{\mathrm{L}} \mathrm{PEI}$ (Figure AM10). The enhancement of sorption properties associated with sulfonation of the sorbent, already demonstrated in the study of $\mathrm{pH}$ effect, is emphasized by the comparison of maximum sorption capacities ( $>7$ times for scandium).

Figure AM11 shows an example of comparison for the modeling Sc (III) sorption isotherms on $\mathrm{S}-\mathrm{A}_{\mathrm{L}} \mathrm{PEI}$. The Langmuir equation roughly fits the sorption isotherm in the whole range of concentrations; however, the initial section of the curve underestimates the sorption capacities. The Freundlich equation fails to fit the initial section and more specifically the saturation plateau; this is obviously explained by the powerlike form of the equation, which is not appropriate for modeling the saturation of the sorbent. The Sips equation, which includes a third-
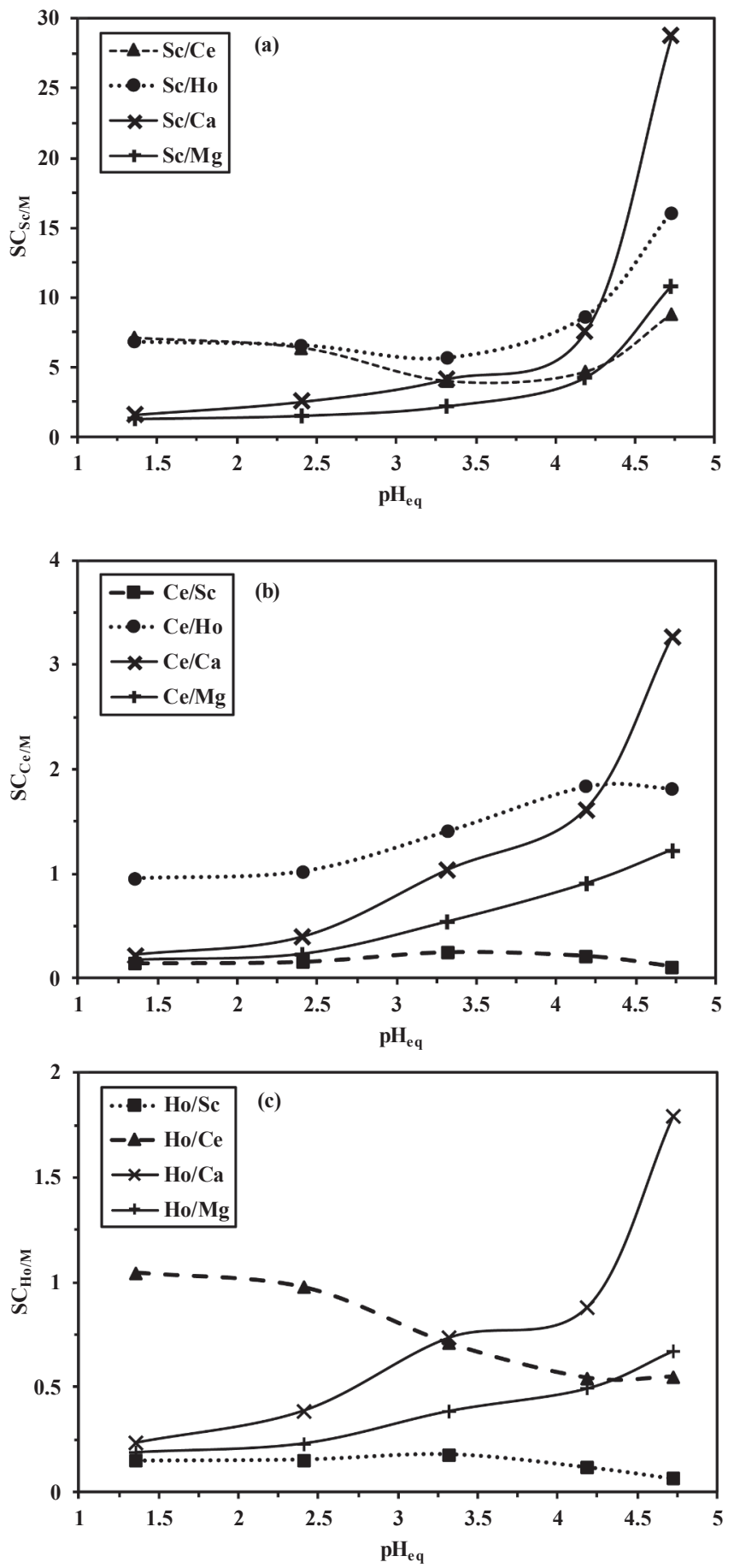

Fig. 6. Selectivity coefficients for Sc(III) (a), Ce(III), and Ho(III) sorption against other metal ions (REEs and alkali-earth $\mathrm{Ca}(\mathrm{II})$ and $\mathrm{Mg}$ (II) metal ions) as a function of equilibrium $\mathrm{pH}$ (equimolar metal concentrations: $1 \mathrm{mmol} \mathrm{L}^{-1}$; SD: $2 \mathrm{~g} \mathrm{~L}^{-1}$; T: $22 \pm 2{ }^{\circ} \mathrm{C}$; contact time: $48 \mathrm{~h}$; agitation speed: $170 \mathrm{rpm}$ ).

adjustable parameter, obviously fits better experimental profiles (especially in the initial section of the curve). This is confirmed, in most cases, by the $\mathrm{R}^{2}$ and AIC values (Table 3 ). However, this mathematical model cannot be directly connected to physicochemical mechanism, contrary to the mechanistic Langmuir equation. This model is thus preferred for fitting data in Fig. 5. However, Table 3 summarizes the parameters for the three models (considering individually the duplicates and the cumulative data for replicates). The sorption capacities at saturation of the monolayer (i.e., $\mathrm{q}_{\mathrm{m}, \mathrm{L}}$ ) slightly overestimates the experimental values (by 18-15\%). The coefficient $b_{L}$ in the Langmuir 
Table 2a

Parameters of models for Sc(III) uptake kinetics.

\begin{tabular}{|c|c|c|c|c|c|c|c|}
\hline & $\mathrm{C}_{0}:\left(\mathrm{mmol} \mathrm{Sc} \mathrm{L} \mathrm{L}^{-1}\right)$ & 0.25 & & 2.36 & & 11.4 & \\
\hline Model & Parameter & $\# 1$ & $\# 2$ & $\# 1$ & $\# 2$ & $\# 1$ & $\# 2$ \\
\hline Exp. & $\mathrm{q}_{\mathrm{eq}}\left(\mathrm{mmol} \mathrm{Sc} \mathrm{g}^{-1}\right)$ & 0.305 & 0.333 & 1.25 & 1.31 & 2.68 & 2.83 \\
\hline \multirow[t]{4}{*}{ PFORE } & $\mathrm{q}_{\mathrm{eq}, 1}\left(\mathrm{mmol} \mathrm{Sc} \mathrm{g}^{-1}\right)$ & 0.306 & 0.326 & 1.32 & 1.35 & 2.80 & 2.96 \\
\hline & $\mathrm{k}_{1} \times 10^{2}\left(\mathrm{~min}^{-1}\right)$ & 14.1 & 16.5 & 8.58 & 9.82 & 10.7 & 10.6 \\
\hline & $\mathrm{R}^{2}$ & 0.991 & 0.973 & 0.983 & 0.995 & 0.983 & 0.983 \\
\hline & AIC & -97.0 & -85.7 & -106.2 & -117.3 & -122.4 & -120.7 \\
\hline \multirow[t]{4}{*}{ PSORE } & $\mathrm{q}_{\mathrm{eq}, 2}\left(\mathrm{mmol} \mathrm{Sc} \mathrm{g}^{-1}\right)$ & 0.358 & 0.368 & 1.67 & 1.68 & 3.46 & 3.66 \\
\hline & $\mathrm{k}_{2} \times 10^{2}\left(\mathrm{~L} \mathrm{mmol}^{-1} \min ^{-1}\right)$ & 47.5 & 62.3 & 5.05 & 5.97 & 3.17 & 2.96 \\
\hline & $\mathrm{R}^{2}$ & 0.984 & 0.988 & 0.971 & 0.983 & 0.961 & 0.962 \\
\hline & AIC & -89.9 & -95.6 & -100.6 & -104.4 & -114.0 & -112.4 \\
\hline \multirow[t]{3}{*}{ RIDE } & $\mathrm{D}_{\mathrm{e}} \times 10^{8}\left(\mathrm{~m}^{2} \min ^{-1}\right)$ & 1.81 & 1.97 & 1.47 & 1.58 & 1.83 & 1.82 \\
\hline & $\mathrm{R}^{2}$ & 0.985 & 0.990 & 0.964 & 0.979 & 0.962 & 0.962 \\
\hline & AIC & -91.3 & -101.1 & -98.2 & -101.1 & -114.0 & -112.3 \\
\hline
\end{tabular}

Table 2b

Parameters of models for Ce(III) uptake kinetics.

\begin{tabular}{|c|c|c|c|c|c|c|c|}
\hline \multirow[b]{2}{*}{ Model } & $\mathrm{C}_{0}:\left(\mathrm{mmol} \mathrm{Ce} \mathrm{L}{ }^{-1}\right)$ & \multicolumn{2}{|l|}{0.25} & \multicolumn{2}{|l|}{0.72} & \multicolumn{2}{|l|}{3.6} \\
\hline & Parameter & $\# 1$ & $\# 2$ & $\# 1$ & $\# 2$ & $\# 1$ & $\# 2$ \\
\hline Exp. & $\mathrm{q}_{\mathrm{eq}}\left(\mathrm{mmol} \mathrm{Ce} \mathrm{g}^{-1}\right)$ & 0.203 & 0.212 & 0.315 & 0.327 & 0.587 & 0.573 \\
\hline \multirow[t]{4}{*}{ PFORE } & $\mathrm{q}_{\mathrm{eq}, 1}\left(\mathrm{mmol} \mathrm{Ce} \mathrm{g}^{-1}\right)$ & 0.223 & 0.226 & 0.329 & 0.337 & 0.602 & 0.581 \\
\hline & $\mathrm{k}_{1} \times 10^{2}\left(\min ^{-1}\right)$ & 6.02 & 7.54 & 10.7 & 11.4 & 12.6 & 17.1 \\
\hline & $\mathrm{R}^{2}$ & 0.989 & 0.984 & 0.987 & 0.995 & 0.995 & 0.997 \\
\hline & AIC & -102.1 & -97.1 & -111.6 & -117.7 & -145.2 & -151.3 \\
\hline \multirow[t]{4}{*}{ PSORE } & $\mathrm{q}_{\mathrm{eq}, 2}\left(\mathrm{mmol} \mathrm{Ce} \mathrm{g}^{-1}\right)$ & 0.301 & 0.292 & 0.405 & 0.410 & 0.717 & 0.666 \\
\hline & $\mathrm{k}_{2} \times 10^{2}\left(\mathrm{~L} \mathrm{mmol}^{-1} \mathrm{~min}^{-1}\right)$ & 17.3 & 24.3 & 27.2 & 29.9 & 20.0 & 32.1 \\
\hline & $\mathrm{R}^{2}$ & 0.986 & 0.978 & 0.967 & 0.979 & 0.980 & 0.978 \\
\hline & AIC & -98.9 & -93.2 & -101.9 & -105.6 & -130.3 & -130.4 \\
\hline \multirow[t]{3}{*}{ RIDE } & $\mathrm{D}_{\mathrm{e}} \times 10^{8}\left(\mathrm{~m}^{2} \mathrm{~min}^{-1}\right)$ & 1.04 & 1.23 & 1.76 & 1.83 & 2.10 & 2.76 \\
\hline & $\mathrm{R}^{2}$ & 0.970 & 0.968 & 0.967 & 0.979 & 0.983 & 0.985 \\
\hline & AIC & -88.9 & -88.0 & -101.4 & -105.6 & -131.8 & -135.6 \\
\hline
\end{tabular}

Table 2c

Parameters of models for Ho(III) uptake kinetics.

\begin{tabular}{|c|c|c|c|c|c|c|c|}
\hline \multirow[b]{2}{*}{ Model } & $\mathrm{C}_{0}:\left(\mathrm{mmol} \mathrm{Ho} \mathrm{L}{ }^{-1}\right)$ & \multicolumn{2}{|l|}{0.25} & \multicolumn{2}{|l|}{0.60} & \multicolumn{2}{|l|}{3.0} \\
\hline & Parameter & $\# 1$ & $\# 2$ & $\# 1$ & $\# 2$ & $\# 1$ & $\# 2$ \\
\hline Exp. & $\mathrm{q}_{\mathrm{eq}}\left(\mathrm{mmol} \mathrm{Ho} \mathrm{g}^{-1}\right)$ & 0.153 & 0.164 & 0.204 & 0.210 & 0.538 & 0.556 \\
\hline \multirow[t]{4}{*}{ PFORE } & $\mathrm{q}_{\mathrm{eq}, 1}\left(\mathrm{mmol} \mathrm{Ho} \mathrm{g}^{-1}\right)$ & 0.151 & 0.160 & 0.228 & 0.237 & 0.544 & 0.560 \\
\hline & $\mathrm{k}_{1} \times 10^{2}\left(\min ^{-1}\right)$ & 9.54 & 9.51 & 6.08 & 6.06 & 12.6 & 13.0 \\
\hline & $\mathrm{R}^{2}$ & 0.965 & 0.977 & 0.980 & 0.984 & 0.997 & 0.998 \\
\hline & AIC & -95.8 & -100.5 & -111.4 & -115.2 & -150.4 & -153.8 \\
\hline \multirow[t]{4}{*}{ PSORE } & $\mathrm{q}_{\mathrm{eq}, 2}\left(\mathrm{mmol} \mathrm{Ho} \mathrm{g}^{-1}\right)$ & 0.181 & 0.195 & 0.314 & 0.324 & 0.645 & 0.660 \\
\hline & $\mathrm{k}_{2} \times 10^{2}\left(\mathrm{~L} \mathrm{mmol}^{-1} \mathrm{~min}^{-1}\right)$ & 62.8 & 54.1 & 15.9 & 15.6 & 22.9 & 23.3 \\
\hline & $\mathrm{R}^{2}$ & 0.977 & 0.985 & 0.969 & 0.974 & 0.989 & 0.993 \\
\hline & AIC & -101.9 & -106.5 & -106.9 & -110.4 & -136.2 & -140.2 \\
\hline \multirow[t]{3}{*}{ RIDE } & $\mathrm{D}_{\mathrm{e}} \times 10^{8}\left(\mathrm{~m}^{2} \mathrm{~min}^{-1}\right)$ & 1.36 & 1.30 & 1.18 & 1.15 & 2.05 & 2.07 \\
\hline & $\mathrm{R}^{2}$ & 0.978 & 0.984 & 0.953 & 0.959 & 0.991 & 0.995 \\
\hline & AIC & -106.1 & -109.7 & -100.8 & -104.1 & -137.9 & -141.7 \\
\hline
\end{tabular}

Table 2d

Parameters of models for RE(III) uptake kinetics (multi-component solutions: $\approx$ $100 \mathrm{mg}$ REE(III) $\mathrm{L}^{-1}$ ).

\begin{tabular}{lllll}
\hline Metal ion & & $\mathrm{Sc}(\mathrm{III})$ & $\mathrm{Ce}(\mathrm{III})$ & $\mathrm{Ho}(\mathrm{III})$ \\
\hline $\mathrm{C}_{0}\left(\mathrm{mmol} \mathrm{L}^{-1}\right)$ & & 2.24 & 0.706 & 0.617 \\
Experimental & $\mathrm{q}_{\mathrm{eq}}\left(\mathrm{mmol} \mathrm{g}^{-1}\right)$ & 0.691 & 0.135 & 0.091 \\
PFORE & $\mathrm{q}_{\mathrm{eq}, 1}\left(\mathrm{mmol} \mathrm{g}^{-1}\right)$ & 0.728 & 0.138 & 0.093 \\
& $\mathrm{k}_{1} \times 10^{2}\left(\mathrm{~min}^{-1}\right)$ & 9.31 & 9.91 & 14.1 \\
& $\mathrm{R}^{2}$ & 0.984 & 0.983 & 0.987 \\
& $\mathrm{AIC}$ & -118.0 & -128.4 & -137.1 \\
PSORE & $\mathrm{q}_{\mathrm{eq}, 2}\left(\mathrm{mmol} \mathrm{g}^{-1}\right)$ & 0.911 & 0.168 & 0.109 \\
& $\mathrm{k}_{2} \times 10^{2}\left(\mathrm{~L} \mathrm{mmol}^{-1} \mathrm{~min}^{-1}\right)$ & 10.3 & 66.4 & 152 \\
& $\mathrm{R}^{2}$ & 0.969 & 0.982 & 0.965 \\
& $\mathrm{AIC}$ & -110.8 & -128.7 & -126.3 \\
$\mathrm{RIDE}$ & $\mathrm{D}_{\mathrm{e}} \times 10^{8}\left(\mathrm{~m}^{2} \mathrm{~min}^{-1}\right)$ & 1.62 & 1.68 & 2.32 \\
& $\mathrm{R}^{2}$ & 0.966 & 0.981 & 0.972 \\
& $\mathrm{AIC}$ & -106.5 & -126.8 & -126.9 \\
\hline
\end{tabular}

Table 2e

Parameters of models for RE(III) uptake kinetics (multi-component solutions: $\approx$ $0.25 \mathrm{mM}$ REE(III) $\mathrm{L}^{-1}$ )

\begin{tabular}{lllll}
\hline Metal ion & & Sc(III) & Ce(III) & Ho(III) \\
\hline Experimental & $\mathrm{q}_{\mathrm{eq}}\left(\mathrm{mmol} \mathrm{g}^{-1}\right)$ & 0.268 & 0.111 & 0.066 \\
PFORE & $\mathrm{q}_{\mathrm{eq}, 1}\left(\mathrm{mmol} \mathrm{g}^{-1}\right)$ & 0.272 & 0.113 & 0.064 \\
& $\mathrm{k}_{1} \times 10^{2}\left(\mathrm{~min}^{-1}\right)$ & 12.6 & 6.9 & 21.2 \\
& $\mathrm{R}^{2}$ & 0.962 & 0.946 & 0.974 \\
& $\mathrm{AIC}$ & -82.8 & -96.5 & -118.9 \\
PSORE & $\mathrm{q}_{\mathrm{eq}, 2}\left(\mathrm{mmol} \mathrm{g}^{-1}\right)$ & 0.325 & 0.140 & 0.071 \\
& $\mathrm{k}_{2} \times 10^{2}\left(\mathrm{~L} \mathrm{mmol}^{-1} \mathrm{~min}^{-1}\right)$ & 43.6 & 53.3 & 40.3 \\
& $\mathrm{R}^{2}$ & 0.951 & 0.953 & 0.986 \\
& $\mathrm{AIC}$ & -79.9 & -99.6 & -126.4 \\
$\mathrm{RIDE}$ & $\mathrm{D}_{\mathrm{e}} \times 10^{8}\left(\mathrm{~m}^{2} \mathrm{~min}^{-1}\right)$ & 1.73 & 1.09 & 2.67 \\
& $\mathrm{R}^{2}$ & 0.950 & 0.951 & 0.984 \\
& $\mathrm{AIC}$ & -78.0 & -100.2 & -122.8 \\
\hline
\end{tabular}


Table 3a

Parameters of models for Sc(III) sorption isotherms on S-A $A_{L}$ PEI beads.

\begin{tabular}{lllll}
\hline Model & Parameter & $\# 1$ & $\# 2$ & Cumul. \\
\hline Experimental & $\mathrm{q}_{\mathrm{m}}\left(\mathrm{mmol} \mathrm{sc} \mathrm{g}^{-1}\right)$ & 2.68 & 2.61 & 2.68 \\
Langmuir & $\mathrm{q}_{\mathrm{m}, \mathrm{L}}\left(\mathrm{mmol} \mathrm{Sc} \mathrm{g}^{-1}\right)$ & 3.21 & 3.12 & 3.16 \\
& $\mathrm{~b}_{\mathrm{L}}\left(\mathrm{L} \mathrm{mmol}^{-1}\right)$ & 0.57 & 0.54 & 0.56 \\
& $\mathrm{R}^{2}$ & 0.991 & 0.986 & 0.985 \\
Freundlich & AIC & -42.4 & -38.1 & -79.4 \\
& $\mathrm{k}_{\mathrm{F}}$ & 1.21 & 1.15 & 1.18 \\
& $\mathrm{n}_{\mathrm{F}}$ & 2.62 & 2.61 & 2.61 \\
& $\mathrm{R}^{2}$ & 0.982 & 0.986 & 0.969 \\
Sips & AIC & -36.6 & -40.7 & -76.8 \\
& $\mathrm{q}_{\mathrm{m}, \mathrm{S}}\left(\mathrm{mmol} \mathrm{Sc} \mathrm{g}^{-1}\right)$ & 3.93 & 4.68 & 4.23 \\
& $\mathrm{~b}_{\mathrm{S}}\left(\mathrm{L} \mathrm{mmol}^{-1}\right)$ & 0.45 & 0.33 & 0.39 \\
& $\mathrm{n}_{\mathrm{S}}$ & 1.36 & 1.61 & 1.48 \\
& $\mathrm{R}^{2}$ & 0.993 & 0.992 & 0.989 \\
& AIC & -43.3 & -42.9 & -88.0 \\
\hline
\end{tabular}

Table 3b

Parameters of models for Ce(III) sorption isotherms on S- $\mathrm{A}_{\mathrm{L}} \mathrm{PEI}$ beads.

\begin{tabular}{lllll}
\hline Model & Parameter & $\# 1$ & $\# 2$ & Cumul. \\
\hline Experimental & $\mathrm{q}_{\mathrm{m}}\left(\mathrm{mmol} \mathrm{Ce}^{-1}\right)$ & 0.61 & 0.61 & 0.61 \\
Langmuir & $\mathrm{q}_{\mathrm{m}, \mathrm{L}}\left(\mathrm{mmol} \mathrm{Ce}^{-1}\right)$ & 0.70 & 0.72 & 0.71 \\
& $\mathrm{~b}_{\mathrm{L}}\left(\mathrm{L} \mathrm{mmol}^{-1}\right)$ & 2.54 & 2.16 & 2.35 \\
& $\mathrm{R}^{2}$ & 0.993 & 0.985 & 0.984 \\
Freundlich & $\mathrm{AIC}$ & -79.6 & -70.3 & -145.4 \\
& $\mathrm{k}_{\mathrm{F}}$ & 0.448 & 0.444 & 0.446 \\
& $\mathrm{n}_{\mathrm{F}}$ & 2.97 & 2.85 & 2.91 \\
& $\mathrm{R}^{2}$ & 0.961 & 0.959 & 0.959 \\
Sips & $\mathrm{AIC}$ & -60.7 & -60.0 & -119.9 \\
& $\mathrm{q}_{\mathrm{m}, \mathrm{S}}\left(\mathrm{mmol} \mathrm{Ce}^{-1}\right)$ & 0.71 & 0.76 & 0.74 \\
& $\mathrm{~b}_{\mathrm{S}}\left(\mathrm{L} \mathrm{mmol}^{-1}\right)$ & 2.36 & 1.78 & 2.04 \\
& $\mathrm{n}_{\mathrm{S}}$ & 1.04 & 1.12 & 1.08 \\
& $\mathrm{R}^{2}$ & 0.993 & 0.985 & 0.984 \\
& $\mathrm{AIC}$ & -75.8 & -66.8 & -143.3 \\
\hline
\end{tabular}

Table 3c

Parameters of models for Ho(III) sorption isotherms on S-A $A_{L}$ PEI beads.

\begin{tabular}{lllll}
\hline Model & Parameter & $\# 1$ & $\# 2$ & Cumul. \\
\hline Experimental & $\mathrm{q}_{\mathrm{m}}\left(\mathrm{mmol} \mathrm{Ho} \mathrm{g}^{-1}\right)$ & 0.53 & 0.52 & 0.53 \\
Langmuir & $\mathrm{q}_{\mathrm{m}, \mathrm{L}}\left(\mathrm{mmol} \mathrm{Ho} \mathrm{g}^{-1}\right)$ & 0.63 & 0.60 & 0.61 \\
& $\mathrm{~b}_{\mathrm{L}}\left(\mathrm{L} \mathrm{mmol}^{-1}\right)$ & 1.68 & 2.11 & 1.88 \\
& $\mathrm{R}^{2}$ & 0.983 & 0.981 & 0.982 \\
Freundlich & $\mathrm{AIC}$ & -72.9 & -72.3 & -142.8 \\
& $\mathrm{k}_{\mathrm{F}}$ & 0.360 & 0.368 & 0.364 \\
& $\mathrm{n}_{\mathrm{F}}$ & 2.45 & 2.64 & 2.55 \\
& $\mathrm{R}^{2}$ & 0.991 & 0.985 & 0.984 \\
Sips & $\mathrm{AIC}$ & -81.0 & -75.6 & -153.0 \\
& $\mathrm{q}_{\mathrm{m}, \mathrm{S}}\left(\mathrm{mmol} \mathrm{Ho}^{-1}\right)$ & 1.20 & 0.910 & 1.03 \\
& $\mathrm{~b}_{\mathrm{S}}\left(\mathrm{L} \mathrm{mmol}{ }^{-1}\right)$ & 0.449 & 0.734 & 0.582 \\
& $\mathrm{n}_{\mathrm{S}}$ & 1.75 & 1.63 & 1.69 \\
& $\mathrm{R}^{2}$ & 0.993 & 0.990 & 0.989 \\
& AIC & -80.6 & -76.5 & -157.8 \\
\hline
\end{tabular}

equation is correlated to the affinity of the sorbent for target metal. The variations of the affinity coefficient do not follow the trends observed for the maximum sorption capacities: $\mathrm{Ce}(\mathrm{III})\left[2.35 \mathrm{~L} \mathrm{mmol}^{-1}\right]>\mathrm{Ho}$ (III) $\left[1.88 \mathrm{~L} \mathrm{mmol}^{-1}\right]>\mathrm{Sc}$ (III) $\left[0.56 \mathrm{~L} \mathrm{mmol}^{-1}\right]$. It is noteworthy that the affinity coefficient is consistently increasing with the $\mathrm{M}-\mathrm{O}$ distance and ionic radius and decreasing with the hydration free energy of selected metal ions (see Table AM7).

Figure AM12 reports the ln plots of the distribution coefficients $v s$. the residual concentrations (mol metal $\mathrm{L}^{-1}$ ). The slopes for the three REEs were very close (ranging between -1.24 and -1.31 ), while the ordinate intercept values confirm the very similar profiles for cerium and holmium (-4.74 and -4.76$)$ about one order of magnitude lower than scandium (-3.77).

Table 4 compares for the three REEs the sorption performances (selected $\mathrm{pH}$, equilibrium time, Langmuir parameters) of $\mathrm{S}-\mathrm{A}_{\mathrm{L}} \mathrm{PEI}$ with literature data. At selected $\mathrm{pH}$, the sorbent shows superior quality to most of reported materials for $\mathrm{Sc}(\mathrm{III})$, with the exception of Q-APEI that shows a little higher sorption capacity (i.e., $\mathrm{q}_{\mathrm{m}, \mathrm{L}}: 4 \mathrm{mmol} \mathrm{Sc}^{-1}$ ) and higher affinity (i.e., $1.26 \mathrm{~L} \mathrm{mmol}^{-1}$ ) but with worst mass transfer performance (equilibrium achieved within $90 \mathrm{~min}$ instead of $40 \mathrm{~min}$ ) [46]. In the case of $\mathrm{Ce}(\mathrm{III})$, many sorbents show higher sorption performances, including biosorbents like crab shells [76], citrus peel and grapefruit peels [77,78] or brown algae [79]. Sorption properties are comparable to an aminophosphonic acid grafted carbon [80]. However, this is HKUST-1, a metal-organic framework (copper benezene-1,3,5tricarboxylate), that shows outstanding properties for $\mathrm{Ce}(\mathrm{III})$ with

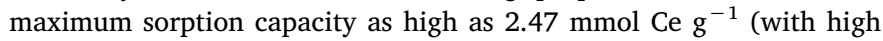
affinity coefficient), though much longer contact time is required for reaching the equilibrium (i.e., about $8 \mathrm{~h}$ ) [81]. Although $S-\mathrm{A}_{\mathrm{L}} \mathrm{PEI}$ shows lower sorption performance for Ho(III) removal compared with other REEs, the sorption performance is significantly better than the values reported for alternative sorbents, (the double of the sorption capacity reported by TVEX-PHOR [82]). The literature on Ho(III) is less abundant than for other REEs and the experimental conditions are very different; the strict comparison is consequently more difficult; anyway, the maximum sorption capacity and the kinetic data demonstrate that $S-A_{L} P E I$ is a promising sorbent for the recovery of Ho(III) from aqueous solutions.

The comparison of sorption performances under similar experimental conditions (similar optimum $\mathrm{pH}$ ) shows that the sorption of Sc (III), Ce(III) and Ho(III) is a little faster for S- $\mathrm{A}_{\mathrm{L}} \mathrm{PEI}$ compared with Dowex 50X8 and Dowex HCR (S/S), two commercial resins bearing the same reactive groups (i.e., sulfonic moieties). Both the equilibrium times and the model parameters confirm this enhancement of mass transfer properties (see Annex in Supplementary Information). The comparison of sorption isotherms also confirm the superiority of the S$\mathrm{A}_{\mathrm{L}} \mathrm{PEI}$ beads, especially for $\mathrm{Sc}(\mathrm{III})$ : the maximum sorption capacity is increased by $60 \%$. For Ce(III) and $\mathrm{Ho}(\mathrm{III})$, the sorption capacities are also little higher (about 20\%). The affinity coefficients are also superior for S-A $\mathrm{A}_{\mathrm{L}} \mathrm{PEI}$ compared with Dowex resins. This comparison confirms the promising perspectives opened by this new material.

Figure AM13 shows the semi-quantitative analysis of the sorbent after the sorption of REEs from mono-component solutions and from multi-component equimolar solutions. These results confirm the higher sorption of REEs according the sequence: $\mathrm{Sc}(\mathrm{III})>\mathrm{Ce}(\mathrm{III})>\mathrm{Ho}(\mathrm{III})$. Obviously, REE/S molar ratio follows the same ranking: 0.210 (Sc) > 0.145 (Ce) $>0.095$ (Ho). In the case of sorbent loading from multicomponent equimolar solution, the molar ratio $\Sigma \mathrm{REES} / \mathrm{S}$ is close to 0.296; the distribution between the three REEs being: $64.3 \%$ for Sc(III), $24.4 \%$ for Ce(III) and only $11.3 \%$ for Ho(III). These results confirm the strong preference of the sorbent for Sc(III). This will be confirmed by more complete study of selectivity coefficients (see below).

\subsubsection{Sorption mechanism}

Summarizing the information collected through FTIR analysis, the study of $\mathrm{pH}$ effect (in relation with $\mathrm{pH}_{\mathrm{PZC}}$ ) and some observations on XPS survey and EDX semi-quantititive analyses, it is possible identifying different modes of interaction between reactive groups present on the functionalized sorbent. This material is constituted of different functional groups present on the two polymers: carboxylic groups (from alginate), amine groups (from PEI), and the grafted sulfonic groups, in addition to the other compounds present (at lesser extent) in the biomass of Laminaria digitata (including fucoidan and sulfonic fucntions, proteins etc.). The typical bands of sulfonic, hydroxyl, amine and carboxylic groups appear to be influenced by (a) decrease in the relative intensity, and/or (b) shift in wavenumber after metal sorption. The direct or cooperative interactions between these reactive groups contribute to varying extent to metal sorption, depending on the $\mathrm{pH}$ (and the deprotonation of relevant reactive groups). Therefore, depending on the $\mathrm{pH}$ different mechanisms of binding may be involved: ion exchange 
Table 3d

Parameters of models for Sc(III), Ce(III) and Ho(III) sorption isotherms on $\mathrm{A}_{\mathrm{L}} \mathrm{PEI}$ beads.

\begin{tabular}{lllll}
\hline Model & Parameter & Sc(III) & Ce(III) & Ho(III) \\
\hline Experimental & $\mathrm{q}_{\mathrm{m}}\left(\mathrm{mmol} \mathrm{g}^{-1}\right)$ & 0.376 & 0.122 & 0.075 \\
Langmuir & $\mathrm{q}_{\mathrm{m}, \mathrm{L}}\left(\mathrm{mmol} \mathrm{g}^{-1}\right)$ & 0.504 & 0.191 & 0.114 \\
& $\mathrm{~b}_{\mathrm{L}}\left(\mathrm{Lmol}^{-1}\right)$ & 0.284 & 0.583 & 0.695 \\
& $\mathrm{R}^{2}$ & 0.975 & 0.976 & 0.986 \\
Freundlich & $\mathrm{AIC}$ & -76.5 & -84.6 & -80.0 \\
& $\mathrm{k}_{\mathrm{F}}$ & 0.132 & 0.066 & 0.042 \\
& $\mathrm{n}_{\mathrm{F}}$ & 2.16 & 1.78 & 1.84 \\
& $\mathrm{R}^{2}$ & 0.984 & 0.955 & 0.981 \\
Sips & $\mathrm{AIC}$ & -102.9 & -95.6 & -100.2 \\
& $\mathrm{q}_{\mathrm{m}, \mathrm{S}}\left(\mathrm{mmol} \mathrm{g}^{-1}\right)$ & 1.51 & 0.157 & 0.137 \\
& $\mathrm{~b}_{\mathrm{S}}\left(\mathrm{L} \mathrm{mmol}^{-1}\right)$ & 0.094 & 0.825 & 0.513 \\
& $\mathrm{n}_{\mathrm{S}}$ & 1.80 & 0.779 & 1.16 \\
& $\mathrm{R}^{2}$ & 0.984 & 0.979 & 0.989 \\
& AIC & -122.2 & -117.7 & -119.0 \\
\hline
\end{tabular}

on protonated amine groups or sulfonic groups, chelation on carboxylate and sulfonate groups, or free amine groups. Scheme 2 shows a summary of these different interaction modes.

\subsubsection{Selectivity studies}

The separation of REEs is a challenge since their very close physicochemical properties require extensive (several operating plateaus) and long procedures for their selective recovery, playing for example on chromatographic separation on specifically functionalized sorbents [29] or using chelating mobile phases (such as EDTA) [83]. In order to evaluate the potential of $\mathrm{S}-\mathrm{A}_{\mathrm{L}} \mathrm{PEI}$ for selective separation of REEs, equimolar solutions containing $\mathrm{Sc}(\mathrm{III}), \mathrm{Ce}(\mathrm{III})$ and $\mathrm{Ho}(\mathrm{III})$, together with alkali-earth metal ions (i.e., $\mathrm{Ca}(\mathrm{II})$ and $\mathrm{Mg}(\mathrm{II})$ ) were tested for metal sorption at different $\mathrm{pH}$ values (Fig. 6). This figure clearly shows the very specific affinity of $\mathrm{S}-\mathrm{A}_{\mathrm{L}} \mathrm{PEI}$ for $\mathrm{Sc}(\mathrm{III})$. Indeed, the selectivity coefficient (defined as the ratio $\mathrm{SC}_{\mathrm{M} 1 / \mathrm{M} 2}=\mathrm{D}_{\mathrm{M} 1} / \mathrm{D}_{\mathrm{M} 2}=$ $\left.\left(\mathrm{q}_{\mathrm{eq}, \mathrm{M} 1} \times \mathrm{C}_{\mathrm{eq}, \mathrm{M} 2} / \mathrm{q}_{\mathrm{eq}, \mathrm{M} 2} \times \mathrm{C}_{\mathrm{eq}, \mathrm{M} 1}\right)\right)$ varies between 3 and 9 in the $\mathrm{pH}$ range 1.4-4.2 for Sc(III) vs. Ce(III) and Ho(III); the selectivity for Sc(III) against alkali-earth metal ions increases with $\mathrm{pH}$ (from 1.4 up to 4-7) in this $\mathrm{pH}$ range. Increasing the equilibrium $\mathrm{pH}$ to 4.7 allows substantially increasing the SC according the following classification: $\mathrm{Ce}(\mathrm{III})$
[8.8] < $\mathrm{Mg}$ (II) [10.8] < Ho(III) [16.1] < Ca(II) [28.8]. In the case of Ce(III), the selectivity coefficient against $\mathrm{Mg}$ (II), $\mathrm{Ho}$ (III) and $\mathrm{Ca}$ (II) also increases with the $\mathrm{pH}$. However, in the case of $\mathrm{Ce}(\mathrm{III}) / \mathrm{Mg}$ (II), the SC never exceeds 1.2: the sorbent has a little preference for $\mathrm{Mg}$ (II) in acidic solutions (below $\mathrm{pH} 4$ ). The sorbent has very close affinity for $\mathrm{Ce}$ (III) and $\mathrm{Ho}$ (III) (consistently with previous observations): the $\mathrm{SC}_{\mathrm{Ce} / \mathrm{Ho}}$ remains in the range 1-1.8, regardless of the $\mathrm{pH}$. The highest selectivity is obtained against $\mathrm{Ca}(\mathrm{II})$ (i.e., $\mathrm{SC}_{\mathrm{Ce} / \mathrm{Ca}} \approx 3.3$ at $\mathrm{pH} 4.7$ ). The lowest selectivity coefficients are obtained for holmium recovery (Fig. 6c), being less than 1 (except against $\mathrm{Ca}(\mathrm{II})$ : $\mathrm{SC}_{\mathrm{Ho} / \mathrm{Ca}}=1.8$ ).

Figure AM14 shows the much higher distribution ratios obtained (almost $0.8 \log$ unit), whatever the $\mathrm{pH}$, for $\mathrm{Sc}(\mathrm{III})$ over $\mathrm{Ce}(\mathrm{III})$ and $\mathrm{Ho}$ (III) (which are remarkably close). The distribution ratios are of the same order of magnitude for $\mathrm{Sc}(\mathrm{III}), \mathrm{Ca}(\mathrm{II})$ and $\mathrm{Mg}(\mathrm{II})$ at $\mathrm{pH} 1.4$; selectivity for Sc(III) is drastically increased compared with alkali-earth metals while increasing the $\mathrm{pH}$. Figure AM15 compares the slope analysis for the plots of distribution ratio (in $\log _{10}$ unit) against equilibrium $\mathrm{pH}$ for the three REEs in mono-component and multicomponent solutions. Compared with Figure AM8, in multicomponent solutions, the slopes of linearized profiles decrease to 0.37 (against 0.62 ) for $\mathrm{Sc}(\mathrm{III})$, 0.38 (against 0.75 ) for $\mathrm{Ce}(\mathrm{III})$ and 0.28 (against 0.43 ) for $\mathrm{Ho}(\mathrm{III})$.

It is noteworthy that the cumulative sorption capacity increases

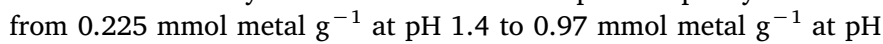
4.7. At $\mathrm{pH} 4.2$ (closer from the equilibrium $\mathrm{pH}$ values reported for mono-component solutions), the residual cumulative metal concentrations is close to $3.3 \mathrm{mmol}$ metal $\mathrm{L}^{-1}$. On the sorption isotherms (in mono-component solutions) for this residual concentration the sorption

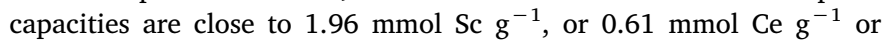

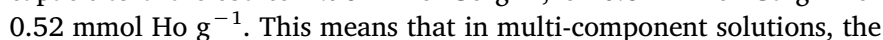
cumulative sorption capacities is considerably decreased compared with Sc(III) sorption isotherm. For the same residual concentration

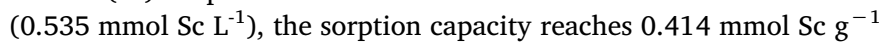

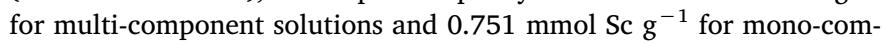
ponent solution.

In conclusion, $\mathrm{S}-\mathrm{A}_{\mathrm{L}} \mathrm{PEI}$ shows a marked preference for $\mathrm{Sc}(\mathrm{III})$ over $\mathrm{Ce}$ (III), $\mathrm{Ho}(\mathrm{III})$ and $\mathrm{Mg}$ (II) and even more against $\mathrm{Ca}(\mathrm{II})$. This preference is significantly improved with $\mathrm{pH}$ increase. The different metal ions compete for the same reactive groups, with a significant decrease of individual and cumulative sorption capacity.

Table 4

Comparison of sorption properties for different sorbents (optimum $\mathrm{pH}$, equilibrium time (min), maximum sorption capacity (experimental of deduced from Langmuir equation), $\mathrm{q}_{\mathrm{m}}\left(\mathrm{mmol} \mathrm{g}{ }^{-1}\right)$, Langmuir affinity constant, $\mathrm{b}_{\mathrm{L}}\left(\mathrm{L} \mathrm{mmol}^{-1}\right)$ ).

\begin{tabular}{|c|c|c|c|c|c|c|}
\hline Metal & Sorbent & $\mathrm{pH}$ & Time & $\mathrm{q}_{\mathrm{m}}$ & $\mathrm{b}_{\mathrm{L}}$ & Ref. \\
\hline \multirow[t]{9}{*}{ Sc } & Lysine-modified SBA-15 & 5 & 10 & 0.667 & 2.19 & [85] \\
\hline & Extractant impregnated resin & 0.78 & 360 & 0.173 & 26.4 & [86] \\
\hline & Extractant impregnated resin & 3 & 300 & 0.36 & 5.68 & [87] \\
\hline & Extractant impregnated resin & 2.5 & 720 & 1.711 & 44.9 & [88] \\
\hline & Cellulose $/ \mathrm{SiO}_{2}$ & 6 & 40 & 0.528 & - & [89] \\
\hline & APEI & 4.5 & 90 & 1.21 & 0.49 & [46] \\
\hline & Q-APEI & 4.5 & 90 & 4.00 & 1.26 & [46] \\
\hline & $\mathrm{TRPO} / \mathrm{SiO}_{2}$ sorbent & 5 & 360 & 0.296 & 31.1 & {$[90]$} \\
\hline & $\mathrm{S}-\mathrm{A}_{\mathrm{L}} \mathrm{PEI}$ & 5 & 40 & 3.16 & 0.56 & This work \\
\hline \multirow[t]{10}{*}{$\mathrm{Ce}$} & Platanum orientalis leaf & 4 & 60 & 0.229 & 21.0 & [91] \\
\hline & Crab shell & 6 & 60 & 1.034 & 6.02 & {$[76]$} \\
\hline & Turbinaria conoides brown algae & 4.9 & 600 & 1.09 & 4.90 & [79] \\
\hline & Citrus reticulata peel & 5 & 60 & 1.162 & 16.1 & [77] \\
\hline & Grapefruit peel & 5 & 60 & 1.137 & 5.28 & [78] \\
\hline & Amino-phosphonic acid activated carbon & 6 & 120 & 0.673 & 0.223 & {$[80]$} \\
\hline & Spirulina biomass & 5 & 180 & 0.272 & 0.841 & [92] \\
\hline & Polypyrrole/wood sawdust & 8 & 120 & 0.047 & 263 & [93] \\
\hline & HKUST-1 metal-organic framework & 6 & 480 & 2.469 & 9.95 & [81] \\
\hline & $\mathrm{S}-\mathrm{A}_{\mathrm{L}} \mathrm{PEI}$ & 5 & 40 & 0.71 & 2.35 & This work \\
\hline \multirow[t]{4}{*}{ Ho } & TVEX-PHOR resin & 3.5 & 90 & 0.306 & - & [82] \\
\hline & Tulsion CH-96 & $0.6 \mathrm{M} \mathrm{H}_{3} \mathrm{PO}_{4}$ & 360 & 0.0213 & 2.31 & [94] \\
\hline & Acid-treated bark powder Mangifera indica & 8 & 180 & 0.0631 & 6.60 & [95] \\
\hline & $\mathrm{S}-\mathrm{A}_{\mathrm{L}} \mathrm{PEI}$ & 5 & 40 & 0.61 & 1.88 & This work \\
\hline
\end{tabular}




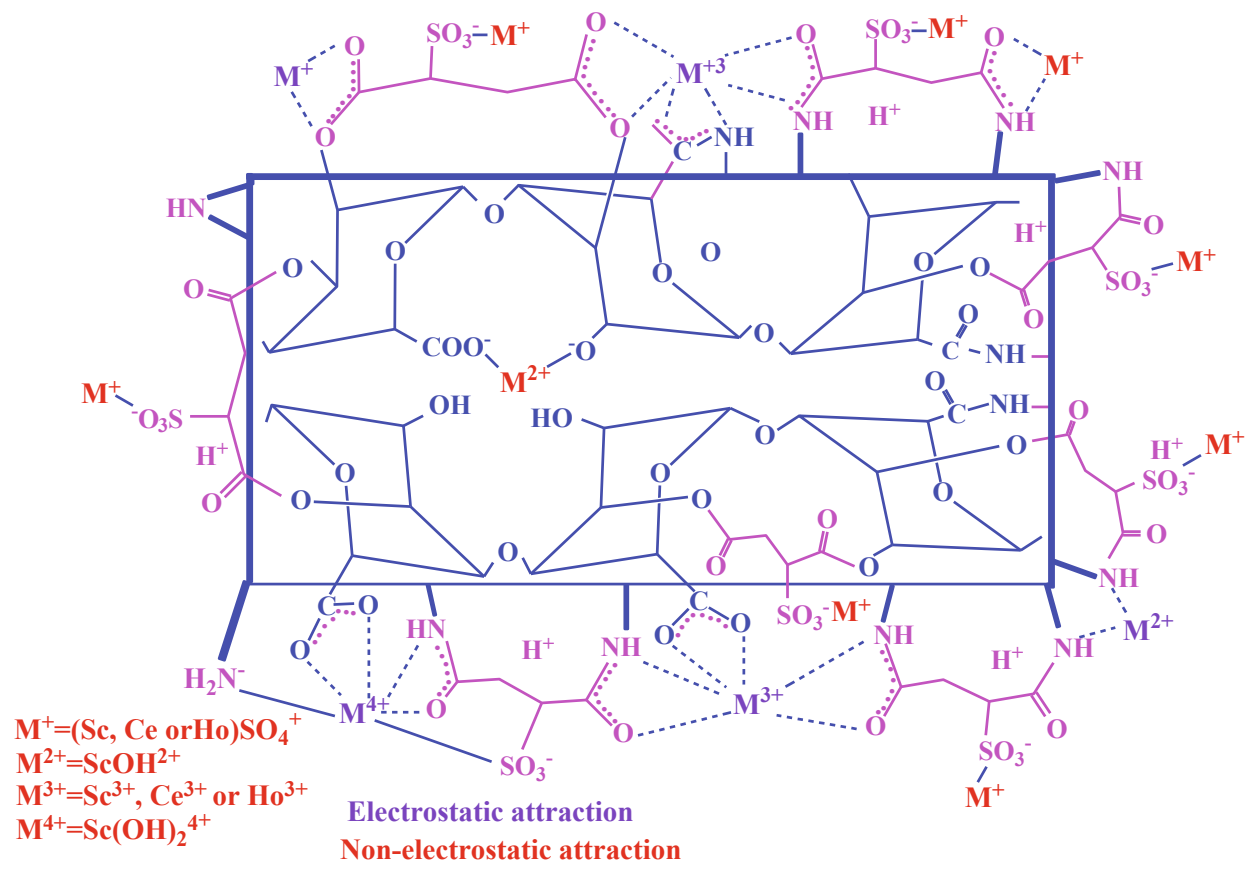

Scheme 2. Suggested mechanisms of interaction between $S-A_{L} P E I$ and REEs metal ions.

Table AM8 shows the semi-quantitative analysis of the surface of SALPEI sorbent after being exposed to Sc(III), Ce(III) and Ho(III) and after contact with the equimolar composite solution (containing the 3 REEs). The greater affinity of the sorbent for Sc(III) over the two other REEs is confirmed by the semi-quantitative analysis on both mono- (Sc (III), 1.09 At $\%>$ Ce(III), $0.84 \%>\mathrm{Ho}(\mathrm{III}), 0.57 \%$ ) and multi-component solutions (Sc(III), 1.08 At \% > Ce(III), $0.41 \%>\mathrm{Ho}(\mathrm{III}), 0.19 \%)$. In multi-component solutions, scandium sorption is maintained at the same level, contrary to $\mathrm{Ce}(\mathrm{III})$ and $\mathrm{Ho}(\mathrm{III})$; the total sorption reaches $1.68 \mathrm{mmol} \mathrm{g}^{-1}$ (Sc: $64.3 \%$; Ce: $24.4 \%$ and Ho: $11.3 \%$ ).

\subsubsection{Metal desorption and sorbent recycling}

The desorption of metal ions from loaded sorbents is a key parameter for designing a sorption process in terms of both metal recovery and valorization, and sorbent recycling. This is a critical step for evaluating the competitiveness of the global process. Based on previous experimentations on algal/PEI based sorbents [45-47], the materials are remarkably stable when using a combination of acid and calcium chloride as the eluent: the presence of calcium chloride improves the ion-exchange of the metals and the stabilization of alginate-based materials (alginate/Ca interaction) [84]. The sorbent samples collected during the study of uptake kinetics were desorbed using a $0.2 \mathrm{M} \mathrm{HCl}$ / $0.5 \mathrm{M} \mathrm{CaCl}_{2}$ solution (Figures AM16 and AM17) for evaluating desorption kinetics. It is noteworthy that desorption is faster than sorption: complete desorption occurs within 15-30 min, depending on the experimental conditions. The kinetic profiles can be modeled using adapted PFORE and PSORE models (Table 5). In Figures AM16 and AM17, the plot of simulated curves clearly shows that none of the two models is appropriate for fitting the totality of the desorption kinetics: the PSORE fits well the beginning of the curves while the PFORE simulates well the second part of the curves. The apparent rates of desorption for the two models are summarized in Table $5 \mathrm{a}$. It is noteworthy that for Sc(III) (and to a lesser extent for Ce(III)), the apparent rate coefficients (both PFORE and PSORE) increase with the concentration of metal loaded on the sorbent while for Ho(III) a reciprocal trend is observed. In the case of the sorbent loaded with multi-component solutions (Figure AM18), the dispersion of data around simulated curves is significantly increased; this is confirmed by lower determination coefficients (Table 5b). The levels of metal loading are different making difficult the comparison of apparent rate coefficients. However, it

Table 5a

Modeling of kinetic profiles for Sc(III), Ce(III) and Ho(III) desorption from loaded S- $\mathrm{A}_{\mathrm{L}}$ PEI beads - PFORE and PSORE model.

\begin{tabular}{|c|c|c|c|c|c|c|c|c|}
\hline Metal ion & Series & $\mathrm{q}_{0}\left(\mathrm{mmol} \mathrm{g}^{-1}\right)$ & $\begin{array}{l}\text { Model } \\
\text { Parameter }\end{array}$ & $\begin{array}{l}\text { PFORE } \\
\mathrm{k}_{\mathrm{D} 1}\left(\min ^{-1}\right)\end{array}$ & $\mathrm{R}^{2}$ & $\begin{array}{l}\text { PSORE } \\
\beta_{2}\end{array}$ & $\mathrm{k}_{\mathrm{D} 2}\left(\min ^{-1}\right)$ & $\mathrm{R}^{2}$ \\
\hline \multirow[t]{4}{*}{ Sc(III) } & $\# 1$ & 1.25 & & 0.142 & 0.969 & 0.992 & 0.279 & 0.955 \\
\hline & $\# 2$ & 1.31 & & 0.142 & 0.959 & 0.998 & 0.299 & 0.961 \\
\hline & $\# 1$ & 2.69 & & 0.243 & 0.972 & 0.995 & 0.497 & 0.969 \\
\hline & $\# 2$ & 2.83 & & 0.229 & 0.971 & 0.994 & 0.463 & 0.963 \\
\hline \multirow[t]{4}{*}{ Ce(III) } & $\# 1$ & 0.288 & & 0.149 & 0.970 & 0.996 & 0.295 & 0.965 \\
\hline & $\# 2$ & 0.325 & & 0.175 & 0.989 & 0.980 & 0.348 & 0.961 \\
\hline & $\# 1$ & 0.587 & & 0.186 & 0.966 & 0.997 & 0.383 & 0.970 \\
\hline & $\# 2$ & 0.573 & & 0.179 & 0.959 & 0.994 & 0.371 & 0.943 \\
\hline \multirow[t]{4}{*}{ Ho(III) } & $\# 1$ & 0.201 & & 0.259 & 0.992 & 0.981 & 0.530 & 0.971 \\
\hline & $\# 2$ & 0.210 & & 0.295 & 0.998 & 0.983 & 0.611 & 0.974 \\
\hline & $\# 1$ & 0.535 & & 0.118 & 0.960 & 0.992 & 0.251 & 0.936 \\
\hline & $\# 2$ & 0.556 & & 0.112 & 0.926 & 1.028 & 0.241 & 0.932 \\
\hline
\end{tabular}

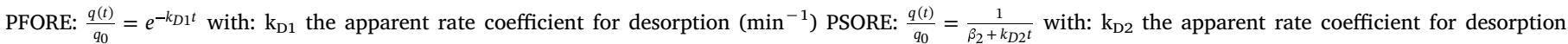
$\left(\min ^{-1}\right.$ ) and $\beta_{2}$ (dimensionless) the constant for PSORE (in desorption). 
Table 5b

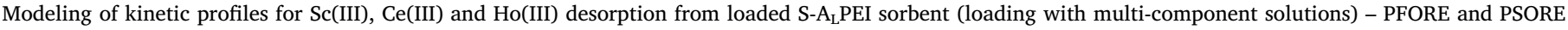
model.

\begin{tabular}{|c|c|c|c|c|c|c|c|}
\hline Metal ion & $\mathrm{q}_{\mathrm{o}}\left(\mathrm{mmol} \mathrm{g} \mathrm{g}^{-1}\right)$ & $\begin{array}{l}\text { Model } \\
\text { Parameter }\end{array}$ & $\begin{array}{l}\text { PFORE } \\
\mathrm{k}_{\mathrm{D} 1}\left(\min ^{-1}\right)\end{array}$ & $\mathrm{R}^{2}$ & $\begin{array}{l}\text { PSORE } \\
\beta_{2}\end{array}$ & $\mathrm{k}_{\mathrm{D} 2}\left(\min ^{-1}\right)$ & $\mathrm{R}^{2}$ \\
\hline $\mathrm{Sc}(\mathrm{III})$ & 0.692 & & 0.196 & 0.990 & 0.973 & 0.426 & 0.954 \\
\hline $\mathrm{Ce}(\mathrm{III})$ & 0.134 & & 0.131 & 0.974 & 0.974 & 0.279 & 0.943 \\
\hline Ho(III) & 0.090 & & 0.094 & 0.891 & 1.037 & 0.193 & 0.900 \\
\hline
\end{tabular}

Table 6

Sorbent desorption and recycling - Sorption (SE, \%) and desorption (DE, \%) efficiencies for $\mathrm{Sc}(\mathrm{III}), \mathrm{Ce}(\mathrm{III})$ and $\mathrm{Ho}(\mathrm{III})$ using $\mathrm{S}-\mathrm{A}_{\mathrm{L}} \mathrm{PEI}$ for five successive cycles.

\begin{tabular}{|c|c|c|c|c|c|c|c|}
\hline \multicolumn{2}{|c|}{ Metal ion } & \multicolumn{2}{|c|}{$\mathrm{Sc}(\mathrm{III})$} & \multicolumn{2}{|c|}{ Ce(III) } & \multicolumn{2}{|c|}{ Ho(III) } \\
\hline Cycle & Av. / St. D & SE & $\mathrm{DE}$ & SE & $\mathrm{DE}$ & SE & $\mathrm{DE}$ \\
\hline \multirow[t]{2}{*}{1} & Av. & 71.6 & 100.2 & 70.8 & 100.4 & 49.6 & 99.9 \\
\hline & St. D. & 0.7 & 0.4 & 0.3 & 0.3 & 2.0 & 0.3 \\
\hline \multirow[t]{2}{*}{2} & Av. & 71.4 & 100.5 & 70.3 & 100.1 & 48.8 & 99.9 \\
\hline & St. D. & 0.3 & 0.3 & 0.5 & 0.4 & 2.3 & 0.9 \\
\hline \multirow[t]{2}{*}{3} & Av. & 70.5 & 100.4 & 69.2 & 100.0 & 48.2 & 99.9 \\
\hline & St. D. & 0.2 & 0.3 & 0.2 & 0.4 & 2.5 & 0.4 \\
\hline \multirow[t]{2}{*}{4} & Av. & 69.5 & 100.7 & 69.0 & 100.0 & 47.5 & 100.1 \\
\hline & St. D. & 0.3 & 0.5 & 0.3 & 0.2 & 2.4 & 0.6 \\
\hline \multirow[t]{2}{*}{5} & Av. & 67.8 & 99.7 & 67.6 & 99.6 & 46.7 & 99.1 \\
\hline & St. D. & 0.2 & 0.2 & 0.2 & 0.2 & 2.1 & 0.1 \\
\hline
\end{tabular}

Av. : average ; St.D. : standard deviation (\%).

Table 7

Pre-treated red mud effluent - Application of S- $A_{L}$ PEI sorbent for metal separation.

\begin{tabular}{llllllll}
\hline \multirow{2}{*}{ Metal } & $\mathrm{C}_{0}\left(\mu \mathrm{mol} \mathrm{L}^{-1}\right)$ & \multicolumn{3}{l}{ Sorption capacity } \\
& & $\mathrm{pH}_{\mathrm{opt}}$ & $\begin{array}{l}\text { Enrichment } \\
\left(\mu \mathrm{qol} \mathrm{g}^{-1}\right)\end{array}$ & $\mathrm{pH}_{\max }$ & $\mathrm{EF}_{\mathrm{pHmax}}$ & $\mathrm{pH} 3.46$ & \\
& & & & & & & \\
\hline $\mathrm{Si}$ & 1,279 & 2.57 & 206 & 2.07 & 14.6 & 0.281 & 179 \\
$\mathrm{Al}$ & 14,945 & 3.46 & 1,301 & 3.46 & 3.80 & 0.451 & 112 \\
$\mathrm{Fe}$ & 154,065 & 3.29 & 1,169 & 2.07 & 0.54 & 0.411 & 1230 \\
$\mathrm{Zn}$ & 532.4 & 2.57 & 130 & 2.07 & 19.7 & 0.585 & 86.3 \\
$\mathrm{Mo}$ & 14.70 & 3.29 & 2.57 & 1.08 & 11.1 & 0.239 & 212 \\
$\mathrm{Zr}$ & 95.14 & 3.46 & 32.1 & 1.08 & 37.4 & 0.688 & 73.4 \\
$\mathrm{Sc}$ & 214.8 & 3.46 & 232 & 1.08 & 53.1 & 50.5 & 1 \\
$\mathrm{Ce}$ & 21.48 & 1.08 & 17.9 & 1.08 & 118 & 43.2 & 2.23 \\
$\mathrm{Gd}$ & 31.59 & 3.46 & 29.0 & 1.08 & 78.9 & 11.8 & 4.27 \\
$\mathrm{Dy}$ & 17.58 & 3.46 & 13.4 & 1.08 & 70.7 & 5.62 & 8.98 \\
$\mathrm{Ho}$ & 4.85 & 3.46 & 2.58 & 1.08 & 19.3 & 2.70 & 18.7 \\
\hline
\end{tabular}

appears that the desorption of Sc(III) is faster for the sorbent loaded in multi-component solutions compared with sorbent loaded from monocomponent solutions, contrary to Ho(III) that follows a reciprocal trend. However, metal desorption is systematically complete, making very attractive the sorbent for metal valorization.

The recycling of the sorbent is investigated along five successive cycles of sorption and desorption (Table 6). It is remarkable that the desorption efficiency remains almost unchanged for the 5 cycles (systematically higher than 99\%). Although a little and progressive decrease in sorption efficiency is observed, the decrease does not exceed $5.3 \%$ for Sc(III), $4.5 \%$ for Ce(III), and $5.8 \%$ for Ho(III), at the fifth cycle. This means that the sorbent is remarkably stable at re-use despite its transfer into solutions of very different acidities and compositions. This is roughly consistent with the observations collected in FTIR studies (Figure AM4). The FTIR is globally maintained though some small changes are observed in the spectrum regions corresponding to C-S (at $\left.518 \mathrm{~cm}^{-1}\right)$, sulfonic $\left(\mathrm{SO}_{3} \mathrm{H}\right.$, at 1138 and $\left.1227 \mathrm{~cm}^{-1}\right)$ and intensity reversal of the bands at $1736 \mathrm{~cm}^{-1}(\mathrm{C}(=\mathrm{O}) \mathrm{O}$ ester stretching vibration) and $1632 \mathrm{~cm}^{-1}(\mathrm{C}=\mathrm{O}$ stretching $/-\mathrm{C}=\mathrm{N}$ stretching vibrations $)$.

\subsection{Application to the treatment of red mud}

Table 7 reports the initial concentrations of a series of heavy metals and REEs identified in red mud solutions. The solution contains high concentrations of heavy metals such as $\mathrm{Fe}$ (i.e., $8.6 \mathrm{~g} \mathrm{Fe} \mathrm{L}^{-1}$ ), $\mathrm{Al}$ (i.e., $403 \mathrm{mg} \mathrm{Al} \mathrm{L}^{-1}$ ), $\mathrm{Zn}$ (i.e., $34.8 \mathrm{mg} \mathrm{Zn} \mathrm{L}^{-1}$ ) and Si (i.e., $35.9 \mathrm{mg} \mathrm{Si} \mathrm{L}^{-1}$ ). In addition, the red mud solution contains about $9.66 \mathrm{mg} \mathrm{Sc} \mathrm{L}^{-1}, 2.99 \mathrm{mg}$ $\mathrm{Ce} \mathrm{L}^{-1}, 4.97 \mathrm{mg} \mathrm{Gd} \mathrm{L}^{-1}, 2.86 \mathrm{mg} \mathrm{Dy} \mathrm{L}^{-1}$ and $0.8 \mathrm{mg} \mathrm{Ho} \mathrm{L}^{-1}$. The optimum $\mathrm{pH}$ range for the sorption of REEs on $\mathrm{S}-\mathrm{A}_{\mathrm{L}} \mathrm{PEI}$ was found at $\mathrm{pH}$ around 3.5 (see Section 3.2.1.). Controlling the $\mathrm{pH}$ to higher values causes metal precipitation or co-precipitation. Figure AM19 shows the abatement of metal concentrations when increasing the initial $\mathrm{pH}$ from 1 to 5 (equilibrium $\mathrm{pH}$ increases from 1.08 to 3.46 ). Metal precipitation remains negligible up to $\mathrm{pH} 2.07$ (except for Ho and Si that precipitate by $25 \%$ and $10 \%$, respectively). Above $\mathrm{pH} 2.5$, the precipitation of metal ions drastically increases at $\mathrm{pH} 3.46$ in the range $16-83 \%$. More specifically, the strong precipitation of iron and aluminum causes the coprecipitation of other heavy metals but also REEs.

Figure AM20 compares the sorption capacities after $48 \mathrm{~h}$ of contact between the $\mathrm{pH}$-adjusted solutions and the sorbent (SD, $0.8 \mathrm{~g} \mathrm{~L}^{-1}$ ). For heavy metals, the huge concentrations of iron and aluminum may explain their high sorption capacities in the range 1-1.3 mmol metal $\mathrm{g}^{-1}$ at the highest $\mathrm{pH}$ values. For $\mathrm{Si}$ and $\mathrm{Zn}$, the sorption increases with the $\mathrm{pH}$ and reaches a maximum at $\mathrm{pH}$ close to 2.56 (sorption capacities in the range $0.1-0.2 \mathrm{mmol} \mathrm{g}^{-1}$ ); much lower values are observed with Mo and $\mathrm{Zr}$ (lower than $0.05 \mathrm{mmol} \mathrm{g}^{-1}$ ). The sorption of scandium also increases with the $\mathrm{pH}$ up to $0.23 \mathrm{mmol} \mathrm{Sc} \mathrm{g}^{-1}$, while the other REEs show much lower sorption (below 0.03 mmol REE $\mathrm{g}^{-1}$ ). The low concentrations of these REEs in the red mud solution and the higher affinity of the sorbent for Sc(III) may explain these very low sorption capacities. Table 7 reports the enrichment factor (EF, defined as the molar fraction of the metal on the sorbent divided by its molar fraction in the initial solution) at the optimum $\mathrm{pH}$ for enrichment (i.e., $\mathrm{pH} 1.08$ for REEs, Mo and $\mathrm{Zr}$, and in the range 2.07-3.46 for other heavy metal ions). High EF values are reported, especially for Ce (118), Gd (78.9) Dy (70.7), Sc (53.1) and $\mathrm{Zr}$ (37.4). Table 7 also shows remarkable values for the distribution ratio ( $\mathrm{D}=\mathrm{q}_{\mathrm{eq}} / \mathrm{C}_{\mathrm{eq}}, \mathrm{L} \mathrm{g}^{-1}$ ) in the case of REEs (2.7-50.5 L $\mathrm{g}^{-1}$ ) while for heavy metals the $\mathrm{D}$ values remain below 0.7 , at $\mathrm{pH}_{\mathrm{eq}}$ : 3.46. The distribution ratio decreases with the atomic weight of the REE for the sequence Ce-Ho. The apparent selectivity coefficient $\mathrm{SC}_{\mathrm{Sc} / \mathrm{Me}}$ $\left(\mathrm{SC}=\mathrm{D}_{\mathrm{Sc}} / \mathrm{D}_{\mathrm{Me}}\right.$; apparent because of the large difference in the concentration of target metal ions) shows an increase in the selectivity of the sorbent for Sc over REEs with their respective atomic weight (from 2.23 to 18.7). In the case of heavy metals, the selectivity is even higher (between 73 for $\mathrm{Zr}$ and up to 1230 for iron).

Table AM9a-b shows the SEM images and semi-quantitative analyses of the surface and crosscut sections of $S-A_{L} P E I$ sorbent after treating red mud solution at different $\mathrm{pH}$ values $(\mathrm{pH} 3-5)$. Table AM10 allows qualitatively identifying the binding of different metal ions from this complex solution, and highlighting the effect of $\mathrm{pH}$. At $\mathrm{pH} \mathrm{3}$, the sorbent has a high affinity for $\mathrm{Fe}, \mathrm{Ti}$ and $\mathrm{Zn}$ (preferentially bound in the core of the sorbent), $\mathrm{Zr}$ and $\mathrm{Al}$ (preferentially at the surface). It is consistent with the relatively high concentrations of these metal ions the solution. Among REEs, Dy shows the highest sorption, which is 
limited to sorbent surface. With increasing the $\mathrm{pH}$ to 4 , the atomic fractions of these elements decrease both at the surface and in the core of the sorbent: $\mathrm{Ti}, \mathrm{Al}$ and $\mathrm{Zn}$ are no more sorbed; the sorption of $\mathrm{Fe}$ and $\mathrm{Zr}$ is halved (preferentially located at the surface of the sorbent). For REEs, the content of Dy strongly decreases while the predominant metals are Sc, Ho and Gd (essentially on the surface of $\mathrm{S}-\mathrm{A}_{\mathrm{L}} \mathrm{PEI}$ ). At $\mathrm{pH}$ 5 , the sorbent maintains good sorption for $\mathrm{Zr}$ (both at the surface and in the core of the sorbent) and Fe (preferentially at the surface). The sorption of REEs is limited to the surface of the sorbent with a predominance of Ho, Dy, Gd and $\mathrm{Nd}$ and a substantial decrease in Sc content. It is noteworthy that Ce uptake is hardly affected by the $\mathrm{pH}$ (maintaining wt\% in the range 0.09-0.12). These results are consistent with (a) the content of these metals in the solution, with the remarkable exception of Al, which is poorly concentrated on the sorbents compared with its high concentration in the red mud solution and (b) the sorption tests. However, these semi-quantitative analyses highlight the heterogeneous distribution of the metals at the surface preferentially to the internal reactive layers (probably associated with the higher density of sulfonic groups at the surface of $S-A_{L} P E I$ ).

\section{Conclusion}

A new support has been designed by the one-pot synthesis of algal/ biomass with polyethyleneimine $\left(\mathrm{A}_{\mathrm{L}} \mathrm{PEI}\right)$ : the interaction of carboxylate groups from alginate extracted from algal biomass with amine groups from PEI, is completed by the inotropic gelation of free carboxylate groups with calcium. The sulfonation of amine groups (with sulfosuccinic acid and poly(ethyleneglycol) diglycidyl ether) strongly increases the affinity of the sorbent $\left(\mathrm{S}-\mathrm{A}_{\mathrm{L}} \mathrm{PEI}\right)$ for REEs. The sorption capacity increases from $0.4 \mathrm{mmol} \mathrm{Sc} \mathrm{g}^{-1}$ to $2.68 \mathrm{mmol} \mathrm{Sc} \mathrm{g}^{-1}$ at the optimum $\mathrm{pH}$ (i.e., $\mathrm{pH}_{0}: 5$ and $\mathrm{pH}_{\mathrm{eq}}$ : $\sim 4$ ). The Langmuir equation remarkably fits the sorption isotherms at least for Sc(III) and Ce(III). Sorption takes place on amine and sulfonate groups through electrostatic and chelation mechanisms as demonstrated by FTIR, XPS techniques, consistently with the surface charge ( $\left.\mathrm{pH}_{\mathrm{PZC}}: 2.86\right)$. The sorbent has a marked preference for Sc(III) over Ce(III) and Ho(III) as shown by sorption tests in equimolar solutions; the selectivity is increased at high $\mathrm{pH}$ values. This selectivity is even better against alkali-earth elements.

Semi-quantitative EDX analysis shows that the material is heterogeneous: stronger density of sulfonate groups at the surface of the beads and higher presence of amine groups in the core of the beads. The material is mesoporous (low specific surface area and large internal pores appearing as polymer scaffolds). This structure may explain that the uptake of REEs is fast: the equilibrium is reached within $30-40 \mathrm{~min}$; although the resistance to intraparticle diffusion is contributing to mass transfer control. The regeneration of the sorbent is highly efficient using an acidic calcium chloride solution: desorption yield exceeds $99 \%$ and the loss in sorption performance does not exceed $6 \%$ at the fifth cycle. The sorbent is remarkably stable in terms of physicochemical properties and sorption performance.

In the last part of this study, the sorbent is applied for the treatment of red mud solutions. After adjusting the $\mathrm{pH}$ (and co-precipitating several heavy metals), the sorption of a number of metals is compared at different $\mathrm{pH}$ values. Due to the large excess of metals such as iron, zirconium, aluminum or zinc, the sorbents are characterized by significant sorption capacities of heavy metals. However, the enrichment factor for REE traces are remarkably high (ranging between 19 and 118 depending on the metals). On the other hand, the distribution ratios ( $\mathrm{L}$ $\mathrm{g}^{-1}$ ) reach 50 for $\mathrm{Sc}(\mathrm{III}), 43$ for $\mathrm{Ce}(\mathrm{III})$ and 3 for $\mathrm{Ho}(\mathrm{III})$ (at $\mathrm{pH} 3.46$ ).

The functionalized sorbent shows remarkable stability at recycling, high efficiency for Sc(III) (and to a lesser extent for other REEs, as demonstrated by the binding of a wide number of rare earths in the red mud solution) and fast kinetics. Though the sorbent is not strictly selective for REEs, the enrichment factors (and distribution ratios) in complex solutions make this new sorbent promising for the recovery and valorization of Sc(III) from industrial solutions. Compared with commercial sulfonic-based resins, $\mathrm{S}$ - $\mathrm{A}_{\mathrm{L}} \mathrm{PEI}$ shows little faster uptake kinetics and higher sorption capacities (especially for $\mathrm{Sc}$ (III) sorption). These promising results would deserve application in fixed-bed reactor for evaluating at pilot-scale the possibility to transfer the process in industry.

\section{CRediT authorship contribution statement}

Mohammed F. Hamza: Methodology, Investigation, Visualization, Supervision. Khalid A.M. Salih: Formal analysis, Data curation, Validation, Investigation. Adel A-H. Abdel-Rahman: Formal analysis, Supervision. Yasser E. Zayed: Validation, Software. Yuezhou Wei: Methodology, Data curation, Investigation, Supervision, Project administration, Funding acquisition. Jie Liang: Software, Formal analysis, Funding acquisition. Eric Guibal: Methodology, Data curation, Visualization, Project administration.

\section{Declaration of Competing Interest}

The authors declare that they have no known competing financial interests or personal relationships that could have appeared to influence the work reported in this paper.

\section{Acknowledgements}

Y. W. thanks the support of NSFC Projects (China) (No.11675102, No.11975082, No U1967218), Science and Technology Major project of Guangxi Province (China) (AA17204100, AA18118030). E.G. and M.F.H acknowledge Institut Francais d'Egypte for supporting the collaboration between IMT-Mines Ales and Nuclear Materials Authority, and IMHOTEP project "MetalValor" (funded by Ministère des Affaires Etrangères and Ministère de l'Enseignement Supérieur et de la Recherche, France); and by Science and Technology Development Fund from Egyptian Academy of Science and Technology, Egypt).

\section{Appendix A. Supplementary data}

Supplementary data to this article can be found online at https:// doi.org/10.1016/j.cej.2020.126399.

\section{References}

[1] European Commission, Waste Electrical \& Electronic Equipment (WEEE), http://ec. europa.eu/environment/waste/strategy.htm, Accessed: 1/9/2017.

[2] N.-K. Ahn, H.-W. Shim, D.-W. Kim, B. Swain, Valorization of waste NiMH battery through recovery of critical rare earth metal: A simple recycling process for the circular economy, Waste Manage. (Oxford) 104 (2020) 254-261.

[3] V. Balaram, Rare earth elements: A review of applications, occurrence, exploration, analysis, recycling, and environmental impact, Geosci. Front. 10 (2019) 1285-1303.

[4] D.T. Buechler, N.N. Zyaykina, C.A. Spencer, E. Lawson, N.M. Ploss, I. Hua, Comprehensive elemental analysis of consumer electronic devices: Rare earth, precious, and critical elements, Waste Manage. (New York, N.Y.), 103 (2019) 67-75

[5] M. Sethurajan, E.D. van Hullebusch, D. Fontana, A. Akcil, H. Deveci, B. Batinic, J.P. Leal, T.A. Gasche, M.A. Kucuker, K. Kuchta, et al., Recent advances on hydrometallurgical recovery of critical and precious elements from end of life electronic wastes-a review, Crit. Rev. Env. Sci. Technol. 49 (2019) 212-275.

[6] N. Swain, S. Mishra, A review on the recovery and separation of rare earths and transition metals from secondary resources, J. Cleaner Prod. 220 (2019) 884-898.

[7] L. Omodara, S. Pitkaaho, E.-M. Turpeinen, P. Saavalainen, K. Oravisjarvi, R.L. Keiski, Recycling and substitution of light rare earth elements, cerium, lanthanum, neodymium, and praseodymium from end-of-life applications - A review, J. Cleaner Prod. 236 (2019).

[8] Z.S. Abisheva, Z.B. Karshigina, Y.G. Bochevskaya, A. Akcil, E.A. Sargelova, M.N. Kvyatkovskaya, I.Y. Silachyov, Recovery of rare earth metals as critical raw materials from phosphorus slag of long-term storage, Hydrometallurgy 173 (2017) 271-282.

[9] A. Akcil, N. Akhmadiyeva, R. Abdulvaliyev, P.M. Abhilash, Overview on extraction and separation of rare earth elements from red mud: Focus on scandium, Miner. Process. Extr. Metall. Rev. 39 (2018) 145-151.

[10] S. Althyabat, P. Zhang, REE extraction from phosphoric acid, phosphoric acid sludge, and phosphogypsum, Miner. Process. Extr. Metall. 124 (2015) 143-150. 
[11] H. Liu, S. Zhang, D. Pan, J. Tian, M. Yang, M. Wu, A.A. Volinsky, Rare earth elements recycling from waste phosphor by dual hydrochloric acid dissolution, J. Hazard. Mater. 272 (2014) 96-101.

[12] M. Walawalkar, C.K. Nichol, G. Azimi, Process investigation of the acid leaching of rare earth elements from phosphogypsum using $\mathrm{HCl}, \mathrm{HNO}_{3}$, and $\mathrm{H}_{2} \mathrm{SO}_{4}$, Hydrometallurgy 166 (2016) 195-204.

[13] J. Spooren, T.A. Atia, Combined microwave assisted roasting and leaching to recover platinum group metals from spent automotive catalysts, Miner. Eng. 146 (2020).

[14] H.S. Yoon, C.J. Kim, K.W. Chung, S.D. Kim, J.R. Kumar, Recovery process development for the rare earths from permanent magnet scraps leach liquors, J. Braz. Chem. Soc. 26 (2015) 1143-1151.

[15] B. Zhang, C. Liu, C. Li, M. Jiang, Separation and recovery of valuable metals from low-grade REE-Nb-Fe ore, Int. J. Miner. Process. 150 (2016) 16-23.

[16] K. Zhou, C. Teng, X. Zhang, C. Peng, W. Chen, Enhanced selective leaching of scandium from red mud, Hydrometallurgy 182 (2018) 57-63.

[17] R. Kim, H. Cho, K.N. Han, K. Kim, M. Mun, Optimization of Acid Leaching of RareEarth Elements from Mongolian Apatite-Based Ore, Minerals 6 (2016).

[18] R. Panda, A. Kumari, M.K. Jha, J. Hait, V. Kumar, J.R. Kumar, J.Y. Lee, Leaching of rare earth metals (REMs) from Korean monazite concentrate, J. Ind. Eng. Chem. 20 (2014) 2035-2042.

[19] S.-G. Zhang, M. Yang, H. Liu, D.-A. Pan, J.-J. Tian, Recovery of waste rare earth fluorescent powders by two steps acid leaching, Rare Met. 32 (2013) 609-615.

[20] T. Vander Hoogerstraete, K. Binnemans, Highly efficient separation of rare earths from nickel and cobalt by solvent extraction with the ionic liquid trihexyl(tetradecyl) phosphonium nitrate: a process relevant to the recycling of rare earths from permanent magnets and nickel metal hydride batteries, Green Chem. 16 (2014) 1594-1606.

[21] S. Wu, L. Wang, P. Zhang, H. El-Shall, B. Moudgil, X. Huang, L. Zhao, L. Zhang, Z. Feng, Simultaneous recovery of rare earths and uranium from wet process phosphoric acid using solvent extraction with D2EHPA, Hydrometallurgy 175 (2018) 109-116.

[22] M. Sharaf, W. Yoshida, F. Kubota, M. Goto, Selective extraction of scandium by a long alkyl chain carboxylic acid/organophosphonic ester binary extractant, Solvent Extr. Ion Exch. 36 (2018) 647-657.

[23] X. Huang, J. Dong, L. Wang, Z. Feng, Q. Xue, X. Meng, Selective recovery of rare earth elements from ion-adsorption rare earth element ores by stepwise extraction with HEH(EHP) and HDEHP, Green Chem. 19 (2017) 1345-1352.

[24] V. Agarwal, M.S. Safarzadeh, Solvent extraction and separation of cerium(III) and samarium(III) from mixed rare earth solutions using PC88A, Miner. Metall. Process 34 (2017) 125-131.

[25] K.L. Ang, D. Li, A.N. Nikoloski, The effectiveness of ion exchange resins in separating uranium and thorium from rare earth elements in acidic aqueous sulfate media. Part 2. Chelating resins, Miner. Eng. 123 (2018) 8-15.

[26] J.-G. Kim, Separation of heavy rare earth elements with extraction chromatography, Curr. Nanosci. 10 (2014) 11-15.

[27] H. Matsunaga, A.A. Ismail, Y. Wakui, T. Yokoyama, Extraction of rare earth elements with 2-ethylhexyl hydrogen 2-ethylhexyl phosphonate impregnated resins having different morphology and reagent content, React. Funct. Polym. 49 (2001) 189-195.

[28] S. Mondal, A. Ghar, A.K. Satpati, P. Sinharoy, D.K. Singh, J.N. Sharma, T. Sreenivas, V. Kain, Recovery of rare earth elements from coal fly ash using TEHDGA impregnated resin, Hydrometallurgy 185 (2019) 93-101.

[29] J. Roosen, K. Binnemans, Adsorption and chromatographic separation of rare earths with EDTA- and DTPA-functionalized chitosan biopolymers, J. Mater. Chem. A 2 (2014) 1530-1540.

[30] J. Roosen, J. Spooren, K. Binnemans, Adsorption performance of functionalized chitosan-silica hybrid materials toward rare earths, J. Mater. Chem. A 2 (2014) 19415-19426.

[31] T. Kegl, A. Kosak, A. Lobnik, Z. Novak, A.K. Kralj, I. Ban, Adsorption of rare earth metals from wastewater by nanomaterials: A review, J. Hazard. Mater. 386 (2020).

[32] A.A. Galhoum, M.G. Mahfouz, S.T. Abdel-Rehem, N.A. Gomaa, A.A. Atia, T. Vincent, E. Guibal, Diethylenetriamine-functionalized chitosan magnetic nanobased particles for the sorption of rare earth metal ions Nd(III), Dy(III) and Yb(III), Cellulose 22 (2015) 2589-2605.

[33] A.A. Galhoum, M.G. Mafhouz, S.T. Abdel-Rehem, N.A. Gomaa, A.A. Atia, T. Vincent, E. Guibal, Cysteine-functionalized chitosan magnetic nano-based particles for the recovery of light and heavy rare earth metals: uptake kinetics and sorption isotherms, Nanomaterials 5 (2015) 154-179.

[34] M.F. Hamza, A.A.H. Abdel-Rahman, E. Guibal, Magnetic glutamine-grafted polymer for the sorption of U(VI), Nd(III) and Dy(III), J. Chem. Technol. Biotechnol. 93 (2018) 1790-1806.

[35] M.J. Page, J.E. Quinn, K.H. Soldenhoff, The impact of sulfate ions on the ion exchange of rare earth elements, Hydrometallurgy 186 (2019) 12-20.

[36] D.D. Miller, R. Siriwardane, D. McIntyre, Anion structural effects on interaction of rare earth element ions with Dowex 50W X8 cation exchange resin, J. Rare Earths 36 (2018) 879-890.

[37] X. Heres, V. Blet, P. Di Natale, A. Ouaattou, H. Mazouz, D. Dhiba, F. Cuer, Selective extraction of rare earth elements from phosphoric acid by ion exchange resins, Metals, 8 (2018) Art. N 682.

[38] K.L. Ang, D. Li, A.N. Nikoloski, The effectiveness of ion exchange resins in separating uranium and thorium from rare earth elements in acidic aqueous sulfate media. Part 1. Anionic and cationic resins, Hydrometallurgy 174 (2017) 147-155.

[39] V.N. Rychkov, E.V. Kirillov, S.V. Kirillov, G.M. Bunkov, M.A. Mashkovtsev, M.S. Botalov, V.S. Semenishchev, V.A. Volkovich, Selective ion exchange recovery of rare earth elements from uranium mining solutions, in: A.A. Rempel, V.A.
Volkovich (Eds.) Physics, Technologies and Innovation, 2016, pp. AIP Conference Proceedings 1767, 020017; doi: 020010.021063/020011.4962601.

[40] J.C. Callura, K.M. Perkins, J.P. Baltrus, N.R. Washburn, D.A. Dzombak, A.K. Karamalidis, Adsorption kinetics, thermodynamics, and isotherm studies for functionalized lanthanide-chelating resins, J. Colloid Interface Sci. 557 (2019) 465-477.

[41] M.J. Page, K. Soldenhoff, M.D. Ogden, Comparative study of the application of chelating resins for rare earth recovery, Hydrometallurgy 169 (2017) 275-281.

[42] M.F. Hamza, I.E. El Aassy, F.Y. Ahmed, A.A.H. Abdel-Rahman, A.M. Atta, Separation of uranium and rare earth elements with high purity from low-grade gibbsite-bearing shale ore by different chelating resins, J. Dispersion Sci. Technol. 33 (2012) 482-489.

[43] D. Fila, Z. Hubicki, D. Kolodynska, Recovery of metals from waste nickel-metal hydride batteries using multifunctional Diphonix resin, Adsorption - J. Int. Ads. Soc. 25 (2019) 367-382.

[44] Y. Privar, I. Malakhova, A. Pestov, A. Fedorets, Y. Azarova, S. Schwarz, S. Bratskaya, Polyethyleneimine cryogels for metal ions sorption, Chem. Eng. J. 334 (2018) 1392-1398.

[45] Y. Wei, K.A.M. Salih, S. Lu, M.F. Hamza, T. Fujita, T. Vincent, E. Guibal, Amidoxime functionalization of algal/polyethyleneimine beads for the sorption of $\mathrm{Sr}$ (II) from aqueous solutions, Molecules, 24 (2019) Art. $\mathrm{N}^{\circ} 3893$.

[46] M.F. Hamza, Y. Wei, E. Guibal, Quaternization of algal/PEI beads (a new sorbent): characterization and application to scandium recovery from aqueous solutions, Chem. Eng. J., 383 (2020) Art. $\mathrm{N}^{\circ} 123210$.

[47] M.F. Hamza, A.E. Mubark, Y. Wei, T. Vincent, E. Guibal, Quaternization of composite algal/PEI beads for enhanced uranium sorption - Application to ore acidic leachate, Gels (Basel, Switzerland), 6 (2020) Art. N 6020012.

[48] J.W. Rhim, H.B. Park, C.S. Lee, J.H. Jun, D.S. Kim, Y.M. Lee, Crosslinked poly(vinyl alcohol) membranes containing sulfonic acid group : proton and methanol transport through membranes, J. Membr. Sci. 238 (2004) 143-151.

[49] Y.S. Ho, G. McKay, Pseudo-second order model for sorption processes, Process Biochem. 34 (1999) 451-465.

[50] J. Crank, The Mathematics of Diffusion, 2nd. ed., Oxford University Press, Oxford, U.K., 1975, p. 414.

[51] C. Tien, Adsorption Calculations and Modeling, Butterworth-Heinemann, Newton, MA, 1994, p. 243.

[52] O. Falyouna, O. Eljamal, I. Maamoun, A. Tahara, Y. Sugihara, Magnetic zeolite synthesis for efficient removal of cesium in a lab-scale continuous treatment system, J. Colloid Interface Sci. 571 (2020) 66-79.

[53] J. Rouquerol, D. Avnir, C.W. Fairbridge, D.H. Everett, J.H. Haynes, N. Pernicone, J. D.F. Ramsay, K.S.W. Sing, K.K. Unger, Recommendations for the Characterization of Porous Solids, in.

[54] S.S. Sun, F. Liang, L.G. Tang, J. Wu, C. Ma, Microstructural investigation of gas shale in Longmaxi Formation, Lower Silurian, NE Sichuan Basin, China, Energy Exploration \& Exploitation 35 (2017) 406-429.

[55] W. Zhan, C.H. Xu, G.F. Qian, G.H. Huang, X.Z. Tang, B.F. Lin, Adsorption of Cu(II), $\mathrm{Zn}(\mathrm{II})$, and $\mathrm{Pb}(\mathrm{II})$ from aqueous single and binary metal solutions by regenerated cellulose and sodium alginate chemically modified with polyethyleneimine, RSC Adv. 8 (2018) 18723-18733.

[56] Y. Akkoz, R. Coskun, A. Delibas, Preparation and characterization of sulphonated bio-adsorbent from waste hawthorn kernel for dye (MB) removal, J. Mol. Liq. 287 (2019) 11.

[57] G. Fan, C. Liao, T. Fang, S. Luo, G. Song, Amberlyst 15 as a new and reusable catalyst for the conversion of cellulose into cellulose acetate, Carbohydr. Polym. 112 (2014) 203-209.

[58] M.F. Hamza, A.A.H. Abdel-Rahman, Extraction studies of some hazardous metal ions using magnetic peptide resins, J. Dispersion Sci. Technol. 36 (2015) 411-422.

[59] M.F. Hamza, M.M. Aly, A.A.H. Abdel-Rahman, S. Ramadan, H. Raslan, S. Wang, T. Vincent, E. Guibal, Functionalization of magnetic chitosan particles for the sorption of U(VI), Cu(II) and Zn(II) - Hydrazide derivative of glycine-grafted chitosan, Materials 10 (2017) 539-560.

[60] J. Coates, Interpretation of Infrared Spectra, A Practical Approach, in: Encyclopedia of Analytical Chemistry, John Wiley \& Sons, Ltd., 2006, pp. 1-23.

[61] C.S. Caetano, M. Caiado, J. Farinha, I.M. Fonseca, A.M. Ramos, J. Vital, J.E. Castanheiro, Esterification of free fatty acids over chitosan with sulfonic acid groups, Chem. Eng. J. 230 (2013) 567-572.

[62] Y. Xiang, M. Yang, Z.B. Guo, Z. Cui, Alternatively chitosan sulfate blending membrane as methanol-blocking polymer electrolyte membrane for direct methanol fuel cell, J. Membr. Sci. 337 (2009) 318-323.

[63] R.M.A. Saboya, J.A. Cecilia, C. Garcia-Sancho, A.V. Sales, F.M.T. de Luna, E. Rodriguez-Castellon, C.L. Cavalcante, Assessment of commercial resins in the biolubricants production from free fatty acids of castor oil, Catal. Today 279 (2017) 274-285.

[64] A.A. Tashvigh, L. Luo, T.-S. Chung, M. Weber, C. Maletzko, A novel ionically crosslinked sulfonated polyphenylsulfone (SPPSU) membrane for organic solvent nanofiltration (OSN), J. Membr. Sci. 545 (2018) 221-228.

[65] Y. Wang, D. Wang, M. Tan, B. Jiang, J. Zheng, N. Tsubaki, M. Wu, Monodispersed hollow $\mathrm{SO}_{3} \mathrm{H}$-functionalized carbon/silica as efficient solid acid catalyst for esterification of oleic acid, ACS Appl. Mater. Interfaces 7 (2015) 26767-26775.

[66] K.S. Siow, L. Britcher, S. Kumar, H.J. Griesser, XPS study of sulfur and phosphorus compounds with different oxidation states, Sains Malaysiana 47 (2018) 1913-1922.

[67] D. Manns, M. Nielsen, A. Bruhn, B. Saake, A. Meyer, Compositional variations of brown seaweeds Laminaria digitata and Saccharina latissima in Danish waters, J. Appl. Phycol. 29 (2017) 1493-1506.

[68] S. Neupane, K.S. Bittkau, S. Alban, Size distribution and chain conformation of six different fucoidans using size-exclusion chromatography with multiple detection, J. 
Chromatogr. A 1612 (2020).

[69] L. Allahgholi, R.R.R. Sardari, S. Hakvag, K.Z.G. Ara, T. Kristjansdottir, I.M. Aasen, O.H. Fridjonsson, T. Brautaset, G.O. Hreggvidsson, E.N. Karlsson, Composition analysis and minimal treatments to solubilize polysaccharides from the brown seaweed Laminaria digitata for microbial growth of thermophiles, J. Appl. Phycol. (2020).

[70] A. Haug, Dissociation of alginic acid, Acta Chem. Scand. 15 (1961) 950-952.

[71] K.D. Demadis, M. Paspalaki, J. Theodorou, Controlled release of bis(phosphonate) pharmaceuticals from cationic biodegradable polymeric matrices, Ind. Eng. Chem. Res. 50 (2011) 5873-5876.

[72] B. Urbano, B.L. Rivas, Poly(sodium 4-styrene sulfonate) and poly(2-acrylamido glycolic acid) polymer-clay ion exchange resins with enhanced mechanical properties and metal ion retention, Polym. Int. 61 (2012) 23-29.

[73] C.K. Liu, R.B. Bai, Q.S. Ly, Selective removal of copper and lead ions by diethylenetriamine-functionalized adsorbent: Behaviors and mechanisms, Water Res. 42 (2008) 1511-1522.

[74] M.A. Hubbe, S. Azizian, S. Douven, Implications of apparent pseudo-second-order adsorption kinetics onto cellulosic materials, A review 2019 (14) (2019) 45.

[75] J.-P. Simonin, On the comparison of pseudo-first order and pseudo-second order rate laws in the modeling of adsorption kinetics, Chem. Eng. J. 300 (2016) 254-263.

[76] K. Vijayaraghavan, R. Balasubramanian, Single and binary biosorption of cerium and europium onto crab shell particles, Chem. Eng. J. 163 (2010) 337-343.

[77] M. Torab-Mostaedi, Biosorption of lanthanum and cerium from aqueous solutions using tangerine (Citrus reticulate) peel: Equilibrium, kinetic and thermodynamic studies, Chem. Ind. Chem. Eng. Q. 19 (2013) 79-88.

[78] M. Torab-Mostaedi, M. Asadollahzadeh, A. Hemmati, A. Khosravi, Biosorption of lanthanum and cerium from aqueous solutions by grapefruit peel: equilibrium, kinetic and thermodynamic studies, Res. Chem. Intermed. 41 (2013) 559-573.

[79] K. Vijayaraghavan, M. Sathishkumar, R. Balasubramanian, Biosorption of lanthanum, cerium, europium, and ytterbium by a brown marine alga, Turbinaria conoides, Ind. Eng. Chem. Res. 49 (2010) 4405-4411.

[80] T. Chen, C. Yan, Y. Wang, C. Tang, S. Zhou, Y. Zhao, R. Ma, P. Duan, Synthesis of activated carbon-based amino phosphonic acid chelating resin and its adsorption properties for Ce(III) removal, Environ. Technol. 36 (2015) 2168-2176.

[81] L. Zhao, M.R. Azhar, X.J. Li, X.G. Duan, H.Q. Sun, S.B. Wang, X.C. Fang, Adsorption of cerium (III) by HKUST-1 metal-organic framework from aqueous solution, J. Colloid Interface Sci. 542 (2019) 421-428.

[82] S.I. El-Dessouky, E.A. El-Sofany, J.A. Daoud, Studies on the sorption of praseodymium (III), holmium (III) and cobalt (II) from nitrate medium using TVEXPHOR resin, J. Hazard. Mater. 143 (2007) 17-23.

[83] R. García Fernández, J.I. García Alonso, Separation of rare earth elements by anionexchange chromatography using ethylenediaminetetraacetic acid as mobile phase, J. Chromatogr. A 1180 (2008) 59-65.

[84] S. Wang, T. Vincent, J.-C. Roux, C. Faur, E. Guibal, Pd(II) and Pt(IV) sorption using alginate and algal-based beads, Chem. Eng. J. 313 (2017) 567-579.

[85] J. Ma, Z. Wang, Y. Shi, Q. Li, Synthesis and characterization of lysine-modified SBA15 and its selective adsorption of scandium from a solution of rare earth elements, RSC Adv. 4 (2014) 41597-41604.

[86] H. Cui, J. Chen, H. Li, D. Zou, Y. Liu, Y. Deng, High-performance polymer-supported extractants with phosphonate ligands for scandium(III) separation, AlChE J. 62 (2016) 2479-2489.

[87] D. Avdibegovic, M. Regadio, K. Binnemans, Recovery of scandium(III) from diluted aqueous solutions by a supported ionic liquid phase (SILP), RSC Adv. 7 (2017) 49664-49674.

[88] S. Bao, W. Hawker, J. Vaughan, Scandium loading on chelating and solvent impregnated resin from sulfate solution, Solvent Extr. Ion Exch. 36 (2018) 100-113.

[89] S. Iftekhar, V. Srivastava, M. Sillanpaa, Enrichment of lanthanides in aqueous system by cellulose based silica nanocomposite, Chem. Eng. J. 320 (2017) 151-159.

[90] Q. Yu, S. Ning, W. Zhang, X. Wang, Y. Wei, Recovery of scandium from sulfuric acid solution with a macro porous TRPO/ $\mathrm{SiO}_{2}-\mathrm{P}$ adsorbent, Hydrometallurgy 181 (2018) 74-81.

[91] S.. Sert, C. Kütahyali, S. İnan, Z. Talip, B. Cetinkaya, M. Eral, Biosorption of lanthanum and cerium from aqueous solutions by Platanus orientalis leaf powder, Hydrometallurgy 90 (2008) 13-18.

[92] D. Sadovsky, A. Brenner, B. Astrachan, B. Asaf, R. Gonen, Biosorption potential of cerium ions using Spirulina biomass, J. Rare Earths 34 (2016) 644-652.

[93] M.A. Olatunji, M.U. Khandaker, H.N.M.E. Mahmud, Investigation of cerium-139 radioisotope adsorption by conducting polymer composite, Polym. Bull. 75 (2018) 2491-2509.

[94] B.R. Reddy, B.N. Kumar, S. Radhika, Solid-liquid extraction of terbium from phosphoric acid medium using bifunctional phosphinic acid resin, Tulsion CH-96, Solvent Extr. Ion Exch. 27 (2009) 695-711.

[95] P.M. Mishra, L. Barick, A.P. Devi, K.K. Swain, Biospecific separation of holmium(III) using raw and chemically treated bark powder of Mangifera indica: kinetics, isotherm and thermodynamic studies, Environ. Technol. (2019), https://doi.org/10. 1080/09593330.2019.1645741. 